\title{
Photoemission and STM study of the electronic structure of $\mathrm{Nb}$-doped $\mathrm{TiO}_{2}$
}

\author{
D. Morris, Y. Dou, J. Rebane, C. E. J. Mitchell, and R. G. Egdell ${ }^{*}$ \\ Inorganic Chemistry Laboratory, South Parks Road, Oxford OX1 3QR, United Kingdom \\ D. S. L. Law \\ Research Unit for Surfaces, Transforms and Interfaces, Daresbury Laboratory, Warrington, Cheshire WA4 4AD, United Kingdom \\ A. Vittadini \\ CSSRCC-CNR, via Marzolo 1, I-35131 Padova, Italy \\ M. Casarin \\ Dipartimento di Chimica Inorganica, Metallorganica ed Analitica, Via Loredan 4, I-35131 Padova, Italy
}

(Received 3 November 1999)

\begin{abstract}
High-resolution core- and valence-level photoemission spectra of Nb-doped $\mathrm{TiO}_{2}$ ceramics $\left(\mathrm{Ti}_{1-x} \mathrm{Nb}_{x} \mathrm{O}_{2}\right.$ with $0.01<x<0.8$ ) have been measured using monochromatic $\mathrm{x}$-ray excitation. Nb doping produces a welldefined photoemission peak in the bulk band gap of rutile, whose intensity increases with increasing doping level. Core-level spectroscopy shows that the $\mathrm{Nb}$ is incorporated within the rutile lattice at low doping levels mainly as $\mathrm{Nb}(\mathrm{V})$ and that the gap state is associated with $\mathrm{Ti}(\mathrm{III})$ ions. This conclusion is reinforced by variable energy photoemission measurements on $\mathrm{Ti}_{0.9} \mathrm{Nb}_{0.1} \mathrm{O}_{2}$ in the vicinity of the $\mathrm{Ti} 3 p$ and $\mathrm{Nb} 4 p$ core thresholds. The photoemission resonance profile for the gap states reaches half maximum intensity at the same energy as found for oxygen-deficient $\mathrm{TiO}_{2-x}$ but is shifted from the resonance profile for the $\mathrm{Nb} 4 d$ states of $\mathrm{NbO}_{2}$. STM images on $\mathrm{Nb}$-doped $\mathrm{TiO}_{2}(110)$ are considered in relation to the spectroscopic measurements. $\mathrm{Nb}$ dopant atoms are imaged as "bright spot" clusters, implying delocalization of charge from $\mathrm{Nb}$ onto neighboring Ti ions. The experimental x-ray photoelectron spectroscopy data are compared with density-of-states profiles derived from local-density approximation calculations on pure and $\mathrm{Nb}$-doped $\mathrm{TiO}_{2}$ clusters. These calculations show that $\mathrm{Nb}$ doping of $\mathrm{TiO}_{2}$ introduces new states of mixed $\mathrm{Nb} 4 d-\mathrm{Ti} 3 d$ character above the $\mathrm{O} 2 p$ valence band of the host material. In addition, there is increased x-ray photoemission intensity across the $\mathrm{O} 2 p$ valence band owing to strong $\mathrm{Nb} 4 d / \mathrm{O} 2 p$ hybridization and a cross section for ionization of $\mathrm{Nb} 4 d$ states that is an order of magnitude larger than that for $\mathrm{O} 2 p$ or Ti $3 d$ states.
\end{abstract}

\section{INTRODUCTION}

Stoichiometric rutile $\left(\mathrm{TiO}_{2}\right)$ is an insulator with a band gap of $3.06 \mathrm{eV}$ at room temperature. The titanium ion achieves it maximal oxidation state and in a formal sense, rutile can be classified as a $3 d^{0}$ oxide. The electronic properties of $d^{0}$ materials are strongly influenced by the introduction of new donor states into the band gap of the host material either by substitutional replacement of the host cation by a cation with a higher $d$-electron count or by oxygen deficiency. Bulk transport measurements show that for very slightly nonstoichiometric $\mathrm{TiO}_{2}$ with a carrier concentration in the range below $2.0 \times 10^{20} \mathrm{~cm}^{-3}$ the low-temperature activation energy for conduction is about $0.028 \mathrm{eV} .{ }^{1}$ For more strongly reduced material a so-called type $b$ activation energy is found that increases with increasing degree of reduction. This unusual behavior is attributed to an aggregation of point defects into shear planes with an enhanced trapping energy at shear plane sites. Obvious substitutional $n$-type dopants for $\mathrm{TiO}_{2}$ are the group- $\mathrm{V}$ elements vanadium, niobium, and tantalum. These elements can be substitutionally incorporated within the rutile lattice to occupy at least $50 \%$ of the cation sites. ${ }^{2-5}$ Indeed both $\mathrm{VO}_{2}$ (Ref. 2) and $\mathrm{NbO}_{2}$ (Refs. 3-5) form a complete range of solid solution with $\mathrm{TiO}_{2}$. Nb doping gives rise to shallow donor states ${ }^{6-9} 0.02-$
$0.03 \mathrm{eV}$ below the conduction-band minimum and therefore at essentially the same energy as the donor states introduced by oxygen deficiency. By contrast, the states associated with $\mathrm{V}$ doping are much deeper in the bulk band gap: both photoemission $^{10,11}$ and photoperturbation of ESR (Refs. 12 and 13) reveal a vertical ionization energy for V-localized donor states of about $2.1 \mathrm{eV}$ relative to the conduction-band minimum. The corresponding adiabatic energy that can be compared directly with transport measurements is $0.8 \mathrm{eV}$. Group V doping can in principle be electronically compensated by cation vacancies or oxygen interstitials whose equilibrium concentration increases dramatically with increasing oxygen fugacity. For V-doped $\mathrm{TiO}_{2}$ it transpires that the degree of compensation is rather small, ${ }^{10,11,14}$ even for samples equilibrated under atmospheric oxygen partial pressure. By contrast $\mathrm{Nb}$-doped ${ }^{15-17}$ and Ta-doped ${ }^{18} \mathrm{TiO}_{2}$ are both much more susceptible to compensation.

Recent technological interest in Nb-doped $\mathrm{TiO}_{2}$ derives from the fact that $\mathrm{Nb}$ doping leads to enhanced photocatalytic activity in the destruction of organochloride pollutants such as dichlorobenzene. ${ }^{19} \mathrm{Nb}$ doping in $\mathrm{TiO}_{2}$ also produces a material with much enhanced catalytic activity in the reduction of $\mathrm{NO}$ by $\mathrm{NH}_{3}$ (Ref. 20) and with an improved response in the sensing of $\mathrm{O}_{2}$ and $\mathrm{H}_{2} \cdot{ }^{21-23}$ The effects of $\mathrm{Nb}$ doping are generally attributed to the introduction of new 
electronic states into the band structure of the parent material whose energy makes them accessible by thermal or photon excitation under the relevant conditions of the technological process.

The simple presumption that $\mathrm{Nb}$ doping introduces shallow donor states into $\mathrm{TiO}_{2}$ at all doping levels was recently called into question by the growth of high-quality (100)(Refs. 24-27) and (110)- (Refs. 25, 28 and 29) oriented single-crystal thin films of $\mathrm{Nb}$-doped $\mathrm{TiO}_{2}$ using oxygenplasma-assisted molecular beam epitaxy. These films displayed excellent long-range order as gauged by low-electron energy diffraction (LEED) and reflection high-energy electron diffraction (RHEED), while it was demonstrated by photoelectron diffraction that the dopant $\mathrm{Nb}$ atoms occupied host Ti sites within the rutile lattice. Contrary to simple expectations, it was found that for doping levels between $x$ $=0.05$ and about $x=0.40$ in material formulated as $\mathrm{Ti}_{1-x} \mathrm{Nb}_{x} \mathrm{O}_{2}$, there was no indication in uv and $\mathrm{x}$-ray excited photoemission spectra of new electronic states in the band gap of the $\mathrm{TiO}_{2}$ host. ${ }^{28,29}$ It was therefore postulated that $\mathrm{Nb}$-induced states must overlap $\mathrm{O} 2 p$ valence-band states. This is extremely surprising in view of the behavior of the system $\mathrm{Ti}_{1-x} \mathrm{Nb}_{x} \mathrm{O}_{2}$ for limiting small and large values of $x$. At the lowest $\mathrm{Nb}$-doping levels it is clear from the transport measurements alluded to above that the dopant introduces shallow donor levels just below the conduction-band minimum of the host material. At the other extreme, in $\mathrm{NbO}_{2}$ itself experimental photoemission spectra demonstrate that there is a distinct $\mathrm{Nb} 4 d$ band above the $\mathrm{O} 2 p$ valence band. ${ }^{30,31}$ Band-structure calculations on $\mathrm{NbO}_{2}$ concur with this model and provide no clues as to why the $4 d$ states in heavily-Nb-doped $\mathrm{TiO}_{2}$ should be very much deeper in energy than in lightly doped material. ${ }^{32}$

Prompted in part by the surprising results of this recent work we report here a study of $\mathrm{Nb}$-doped $\mathrm{TiO}_{2}$ using highresolution $\mathrm{x}$-ray photoemission, variable photon energy resonance photoemission in the vacuum-uv regime, and scanning tunneling microscopy (STM). The photoemission spectra are considered in relation to cross-section-weighted density of states profiles for pure and $\mathrm{Nb}$-doped $\mathrm{TiO}_{2}$ clusters obtained from density-functional calculations. Most of the experimental work is carried out on ceramic polycrystalline material whose bulk oxygen stoichiometry can be precisely defined by a preparative procedure that reacts $\mathrm{TiO}_{2}$ and $\mathrm{NbO}_{2}$ in sealed quartz tubes. The study embraces the complete composition range in the system $\mathrm{Ti}_{1-x} \mathrm{Nb}_{x} \mathrm{O}_{2}$ between $x=0$ and $x=1$. We have also studied $\mathrm{TiO}_{2}$ single crystals doped to a low level by a diffusional technique. It is demonstrated that the conclusions to be drawn from the work on polycrystalline material are in accord with experiments on single-crystal samples.

\section{EXPERIMENT}

$\mathrm{NbO}_{2}$ was prepared by reduction of $\mathrm{Nb}_{2} \mathrm{O}_{5}$ in flowing $\mathrm{Ar} / 5 \% \mathrm{H}_{2}$ at $1200{ }^{\circ} \mathrm{C}$. The material prepared in this way gave the $\mathrm{X}$-ray powder diffraction pattern expected ${ }^{33}$ for the roomtemperature phase belonging to space group $I 4_{1} / a$. $^{34}$ Samples of $\mathrm{Ti}_{1-x} \mathrm{Nb}_{x} \mathrm{O}_{2}$ were prepared by reaction between an intimately ground mixture of $\mathrm{NbO}_{2}$ and $\mathrm{TiO}_{2}$ in evacuated and sealed quartz tubes. The required mixture was ground together in an agate mortar and pestle and fired first at $650{ }^{\circ} \mathrm{C}$ for 1 day and then at $950{ }^{\circ} \mathrm{C}$ for 2 days. The mixture was then reground and refired at $1000{ }^{\circ} \mathrm{C}$ for a further 5 days. Finally the resulting material was formed into pellets by pressing between $\mathrm{WC}$ dies at 10 tonnes, and the resulting "green bodies" were sintered at $1000{ }^{\circ} \mathrm{C}$ in UHV (base pressure $10^{-10}$ mbar). Heating at this stage was achieved with the aid of a water-cooled copper work coil coupled to a $1.5-\mathrm{kW}$ radio-frequency generator. Doped samples with $x$ up to 0.6 gave simple powder $\mathrm{x}$-ray diffraction patterns characteristic of a well-crystallized rutile phase. For $x=0.8$ there was evidence of an onset of the crystallographic distortions, which lead to pairing of $\mathrm{Nb}$ atoms along the $c$ axis in $\mathrm{NbO}_{2}$ itself. The present observations are in accord with the phase diagrams proposed by Sakata $^{4}$ and Rüdorff and Luginsland ${ }^{3}$ who reported onset of structural distortion around $x=0.85$ and $x=0.75$, respectively.

Single-crystal measurements were performed on (110)and (210)-oriented single-crystal slices of $\mathrm{TiO}_{2}$ (Pikem, Hereford, U.K.) that had been doped by a diffusional technique. A crystal slice of typical dimension $10 \mathrm{~mm} \times 10 \mathrm{~mm} \times 1 \mathrm{~mm}$ was packed in excess $1 \% \mathrm{Nb}$-doped $\mathrm{TiO}_{2}$ powder prepared as above and sealed into an evacuated quartz ampoule. The crystals were then soaked in the doped powder at $1000{ }^{\circ} \mathrm{C}$ for 10 days. At the end of this time the crystals were extracted from the quartz tubes. To remove any loosely held sintered powder from the surface the crystals were polished with progressively finer diamond paste down to $1 \mu \mathrm{m}$ using a water-based polishing fluid and were then rinsed ultrasonically in isopropanol and double distilled water.

High-resolution x-ray photoemission spectra were measured in a Scienta ESCA 300 spectrometer. ${ }^{35}$ This incorporates a rotating-anode $\mathrm{Al} K \alpha(h v=1486.6 \mathrm{eV})$ x-ray source, a seven-crystal x-ray monochromator, and a $300-\mathrm{mm}$ mean radius spherical sector electron energy analyzer with a parallel electron detection system. The x-ray source was run with 200-mA emission current and 14-kV anode bias, while the analyzer operated at $150-\mathrm{eV}$ pass energy with $0.5-\mathrm{mm}$ slits. Gaussian convolution of the analyzer resolution with a linewidth of $260 \mathrm{meV}$ for the $\mathrm{x}$-ray source gives an effective instrument resolution of $350 \mathrm{meV}$.

Ceramic pellets of $\mathrm{Nb}$-doped $\mathrm{TiO}_{2}$ and reference samples of $\mathrm{Nb}_{2} \mathrm{O}_{5}$ and $\mathrm{NbO}_{2}$ were cleaned in situ in the preparation chamber of the Scienta spectrometer by annealing in UHV at about $750{ }^{\circ} \mathrm{C}$ for $2-3 \mathrm{~h}$, heating being effected by an electron-beam heater. Doped and undoped (110)- and (210)oriented single crystals were also studied in the Scienta spectrometer. Binding energies are referenced to the Fermi energy of an ion-bombarded silver foil that is regularly used to calibrate the spectrometer and should be accurate to \pm 0.05 $\mathrm{eV}$. There was no indication of sample charging during the $\mathrm{x}$-ray photoelectron spectroscopy (XPS) measurements.

Vacuum-uv photoemission spectra of ceramic $\mathrm{Nb}_{0.1} \mathrm{Ti}_{0.9} \mathrm{O}_{2}$ and $\mathrm{NbO}_{2}$ were measured on beamline 6.2 of the synchrotron radiation source at the Daresbury Laboratory. This incorporated a monochromator with two sets of toroidal gratings covering the photon energy ranges $15-40$ $\mathrm{eV}$ (710 lines/mm) and 40-140 eV (1800 lines/mm). The energy analyzer is housed in a chamber that achieved a base pressure of $2 \times 10^{-10}$ mbar during the experimental run. The 
analyser has $150^{\circ}$ spherical sector deflection elements of mean radius $50 \mathrm{~mm}$. Constant-initial-state (CIS) spectra were measured by scanning the analyzer synchronously with the high-energy monochromator to keep fixed on a constant initial state. For these scans the photon bandwidth was set at 0.5 $\mathrm{eV}$. Count rates were normalized relative to the drain current from a tungsten mesh through which the beam passed just prior to hitting the sample. To construct the CIS curves the raw data were further corrected for the quantum efficiency of the beam monitor mesh, which had in turn been calibrated by measuring the drain current from a copper foil in the photoemission chamber as described in detail elsewhere. ${ }^{36}$

Finally STM measurements on diffusionally Nb-doped $\mathrm{TiO}_{2}(110)$ were carried out in a commercial Omicron UHV STM operating at room temperature. ${ }^{37}$ Electrochemically etched tungsten tips were used in all experiments. The STM is mounted in a UHV chamber with a base pressure of 4 $\times 10^{-11}$ mbar. The chamber was equipped with facilities for XPS and LEED. Annealing was performed by radiative heating on the rear side of the mount. The initial cleaning of the surface was achieved with repeated cycles of Ar-ion sputtering $(1.4 \mathrm{kV}, 10 \mu \mathrm{A}, 30 \mathrm{~min})$ and annealing $\left(700^{\circ} \mathrm{C}, 20 \mathrm{~min}\right)$ until LEED patterns indicated a well-ordered $(1 \times 1)$ surface, and no impurities could be detected by XPS or STM imaging.

\section{RESULTS}

\section{A. High-resolution x-ray photoemission of $\mathrm{Nb}_{2} \mathrm{O}_{5}$ and $\mathrm{NbO}_{2}$}

Valence-band photoemission spectra of $\mathrm{Nb}_{2} \mathrm{O}_{5}$ and $\mathrm{NbO}_{2}$ are shown in Fig. 1, while corresponding Nb3d core-level spectra are shown in Fig. 2. The valence-band spectrum of $\mathrm{Nb}_{2} \mathrm{O}_{5}$ is dominated by a single broad feature associated with $\mathrm{O} 2 p$ states, although very weak structure is just visible close to the Fermi energy. This is derived from Nb4 $d$ states introduced by oxygen deficiency. The valence-band onset is at $3.45 \pm 0.05 \mathrm{eV}$. This compares with a quoted bulk band gap of $3.41 \mathrm{eV} .^{38}$ Thus the photoemission data are consistent with a Fermi level pinned close to the conduction-band minimum by the donor states. The corresponding $\mathrm{Nb} 3 d$ corelevel spectrum for $\mathrm{Nb}_{2} \mathrm{O}_{5}$ is shown in Fig. 2. The spectrum is basically a simple spin-orbit doublet with a $\mathrm{Nb} 3 d_{5 / 2}$ binding energy of $207.8 \mathrm{eV}$ relative to the Fermi level. An extremely weak low-binding-energy shoulder is apparent, presumably associated with the $\mathrm{Nb}$ (IV) arising from the oxygen vacancies. The lower panel of Fig. 1 shows the valence-band XPS of $\mathrm{NbO}_{2}$. In addition to the valence-band peak, a sharp and well-defined peak appears close to the Fermi energy. This is associated with the $\mathrm{Nb} 4 d$ states of this $4 d^{1}$ material.

$\mathrm{NbO}_{2}$ adopts a distorted rutile structure $33,34,39,40$ with a narrow homogeneity range at room temperature. ${ }^{41}$ This phase is nonmetallic with an activation energy for conduction of $0.26 \mathrm{eV}^{42}$ A transformation to an undistorted rutile phase takes place at $1070 \mathrm{~K}$ (Refs. 33, 34, and 40) with a large increase in conductivity suggestive of a nonmetal to metal transition. ${ }^{42}$ Although earlier work described the transition to be first order, more recent neutron-diffraction studies suggest a second-order transition. ${ }^{43}$ The nonmetallic behavior of the distorted room-temperature phase is best understood in terms of metal-metal bonding between $\mathrm{Nb}$ ions, which are paired along the $c$ axis within the rutile struc-

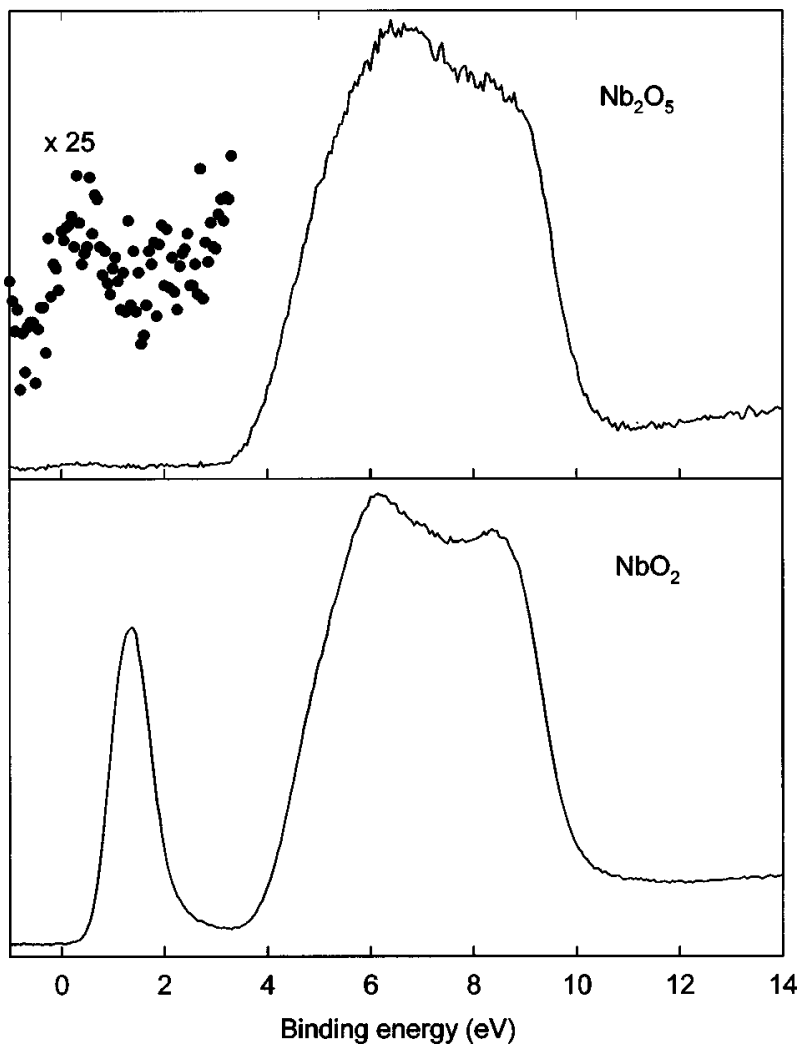

FIG. 1. Valence-band x-ray photoemission spectra of $\mathrm{Nb}_{2} \mathrm{O}_{5}$ and $\mathrm{NbO}_{2}$. Binding energies are relative to the Fermi energy of a calibrant silver foil.

ture. This produces a splitting of the manifold of $4 d$ bands to leave a lowest $\mathrm{Nb}-\mathrm{Nb} \sigma$-bonding band that can accommodate two electrons per pair of $\mathrm{Nb}$ ions. This band is therefore full in $\mathrm{NbO}_{2}$, leading to the observed nonmetallic behavior. ${ }^{42,44}$ The onset of the $\mathrm{Nb} 4 d$ band in the experimental photoemission spectrum is $0.14 \mathrm{eV}$ below the Fermi energy. Given the activation band gap of $0.26 \mathrm{eV}$ alluded to above, the present data suggest that the Fermi level sits in the middle of the narrow gap produced by the room-temperature structural distortion.

The $\mathrm{Nb} 4 d$ core-level spectrum of $\mathrm{NbO}_{2}$ shown in Fig. 2 displays a complex core line shape, broadly in agreement with that reported earlier ${ }^{45}$ given the improved resolution of the present work. The spectral structure is best interpreted in terms of final-state screening effects. Following Kotani and Toyazawa ${ }^{46}$ and Wertheim and co-workers, ${ }^{47,48}$ we recognize that ionization of a core level in a narrow-band metallic oxide $^{45}$ leads to a core-valence Coulomb interaction that may exceed the conduction-band width. In this situation the potential associated with the core hole will be sufficient to pull a localized level at the ionized site out of the metallic conduction band to produce a localized trap state. A "wellscreened" final state is obtained if this trap level is occupied in the final state, but if the localized level remains empty a "poorly screened" final state is obtained. For a narrow band $d^{n}$ oxide, the "well-screened" and "poorly screened" final states differ by one in their $d$-electron count. This model is readily extended to systems where structural distortion opens a small gap in the one-electron band structure, provided that the magnitude of the gap is much less than the core-valence 


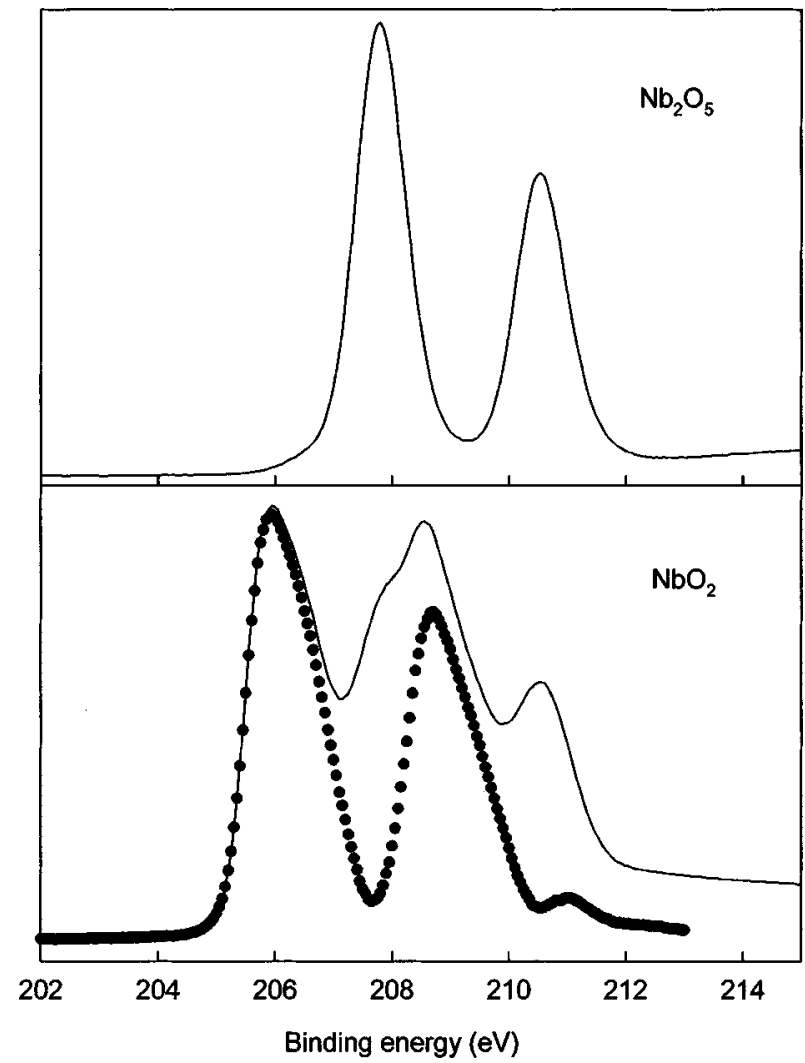

FIG. 2. $\mathrm{Nb} 3 d$ core $\mathrm{x}$-ray photoemission spectra of $\mathrm{Nb}_{2} \mathrm{O}_{5}$ and $\mathrm{NbO}_{2}$. The dots in the lower panel spectrum of $\mathrm{NbO}_{2}$ correspond to the contribution to the spectral signal from screened final states. This is obtained by subtraction of a suitably weighted backgroundsubtracted $\mathrm{Nb}_{2} \mathrm{O}_{5}$ spectrum from the $\mathrm{NbO}_{2}$ spectrum. Binding energies are relative to the Fermi energy of a calibrant silver foil.

Coulomb interaction. In the present case the binding energies of the spin-orbit components associated with poorly screened final state coincide with those found for $\mathrm{Nb}_{2} \mathrm{O}_{5}$, so that the poorly screened state corresponds to a $4 d^{0}$ final-state configuration. The structure associated with the well-screened final-state configuration may be obtained simply by subtracting an appropriately weighted $4 d^{0}$ spectrum from the composite spectral profile. This procedure leads to a clean spinorbit doublet associated with the well-screened final state, aside from a weak peak to high binding energy that arises from subtle changes in the photoemission background. As expected from the Kotani model, the structure associated with the well-screened final state shows pronounced asymmetry in the line shape, reminiscent of the asymmetric Doniach-Sunjic line shape found for simple metals. The $0.26-\mathrm{eV}$ threshold for electron-hole pair excitations in $\mathrm{NbO}_{2}$ accentuates this asymmetry.

Despite the appeal of the physical model, the KotaniWertheim model has not gained total acceptance (especially in the catalytic literature) and there has been a recurring temptation to interpret core photoemission spectra of narrowband metallic (or near-metallic) oxides in terms of the requirement that each distinct final-state $d^{n}$ configuration must arise from a corresponding initial-state $d^{n}$ configuration. This in turn leads to interpretation of complex spectral profiles in terms of contamination of the intrinsic material by ill-defined "surface phases" within which the oxidation state of the metal cation differs from that of the parent bulk phase. Recent experiments ${ }^{49}$ on single-crystal $\mathrm{RuO}_{2}$ grown by molecular beam epitaxy (MBE) on $\mathrm{TiO}_{2}(110)$ substrates revealed a complex $\mathrm{Ru} 4 d$ spectral profile qualitatively similar to that for $\mathrm{NbO}_{2}$. The screened and unscreened components of the complex core line showed the same azimuthal variations in intensity in a photoelectron diffraction experiment. This experiment provides a definitive demonstration that the photoemitting atoms that give rise to the screened and unscreened peaks occupy identical crystallographic sites. The clear-cut situation with respect to the $\mathrm{Ru} 4 d$ core line shape for $\mathrm{RuO}_{2}$ gives us confidence in our interpretation of the complex line shape found for $\mathrm{NbO}_{2}$ in terms of the Kotani-Wertheim model.

\section{B. X-ray photoemission spectra of $\mathrm{Ti}_{1-x} \mathrm{Nb}_{x} \mathrm{O}_{2}$}

Valence-band photoemission spectra of the $\mathrm{Ti}_{1-x} \mathrm{Nb}_{x} \mathrm{O}_{2}$ ceramics are shown in Fig. 3(a). Even at the lowest doping level a weak peak is apparent in the bulk band gap of the rutile host material. This peak grows in intensity monotonically with increasing doping level, converging on the intensity of the $4 d$ peak found for $\mathrm{NbO}_{2}$. The binding energy of the gap feature shows a small downward shift with increasing doping level. At $1 \%$ doping level, the peak maximum is at $0.8 \mathrm{eV}$. This is close to the vertical ionization energy of $1.0 \mathrm{eV}$ for Ti $3 d$ states in oxygen-deficient $\mathrm{TiO}_{2-x} \cdot{ }^{50}$ At the highest $\mathrm{Nb}$-doping level of $80 \%$ the peak maximum is at $1.40 \mathrm{eV}$ binding energy, as found for $\mathrm{NbO}_{2}$ itself. These findings accord with onset of the structural distortion that leads to $\mathrm{Nb}-\mathrm{Nb}$ bonding at a doping level of around $80 \%$. The oxygen valence-band onset energy also shows a progressive shift to high binding energy with $\mathrm{Nb}$ doping. For undoped $\mathrm{TiO}_{2}$ the valence-band onset as gauged by a simple linear extrapolation of the valence-band edge is 3.08 $\pm 0.05 \mathrm{eV}$, in accord with the bulk band gap and a placement of the Fermi level very close to the conduction-band minimum. The increase of the binding energy of the $\mathrm{O} 2 p$ onset with $\mathrm{Nb}$ doping then implies a widening of the bulk gap, an effect that can be understood in terms of stronger mixing between $\mathrm{Nb} 4 d$ and $\mathrm{O} 2 p$ states than between $\mathrm{Ti} 3 d$ and $\mathrm{O}$ $2 p$ states. As indicated previously the band gap for $\mathrm{TiO}_{2}$ is smaller than that for $\mathrm{Nb}_{2} \mathrm{O}_{5}$.

The $\mathrm{Nb} 3 d$ and Ti $2 p$ core-level spectra corresponding to the valence-band spectra of Fig. 3 are shown in Figs. 4 and 5 respectively. The $\mathrm{Nb} 3 d$ structure is presented with intensities scaled to the $\mathrm{O} 1 s$ intensity. As expected, the absolute $\mathrm{Nb} 3 d$ intensity increases with increasing doping level. However, there is also a striking evolution of the $\mathrm{Nb} 3 d$ line shape from a simple spin-orbit doublet at low doping level toward the complex spectral profile of $\mathrm{NbO}_{2}$ at the highest doping level. Figure 5 shows that there are also changes in the Ti $2 p$ spectral profile with doping. The Ti $2 p$ spectrum of nominally undoped vacuum annealed $\mathrm{TiO}_{2}$ already has very weak low-binding-energy shoulders with about $2 \%$ of the intensity of the dominant spin-orbit doublet. These arise from $\mathrm{Ti}(\mathrm{III})$ states introduced by oxygen deficiency in the near-surface region probed by XPS. Since each oxygen vacancy introduces two donor $3 d^{1} \mathrm{Ti}(\mathrm{III})$ levels, the surface stoichiometry must be of the order $\mathrm{TiO}_{1.99}$. The Ti(III) shoulders grow in intensity with increasing $\mathrm{Nb}$ doping. The Ti $2 p$ 

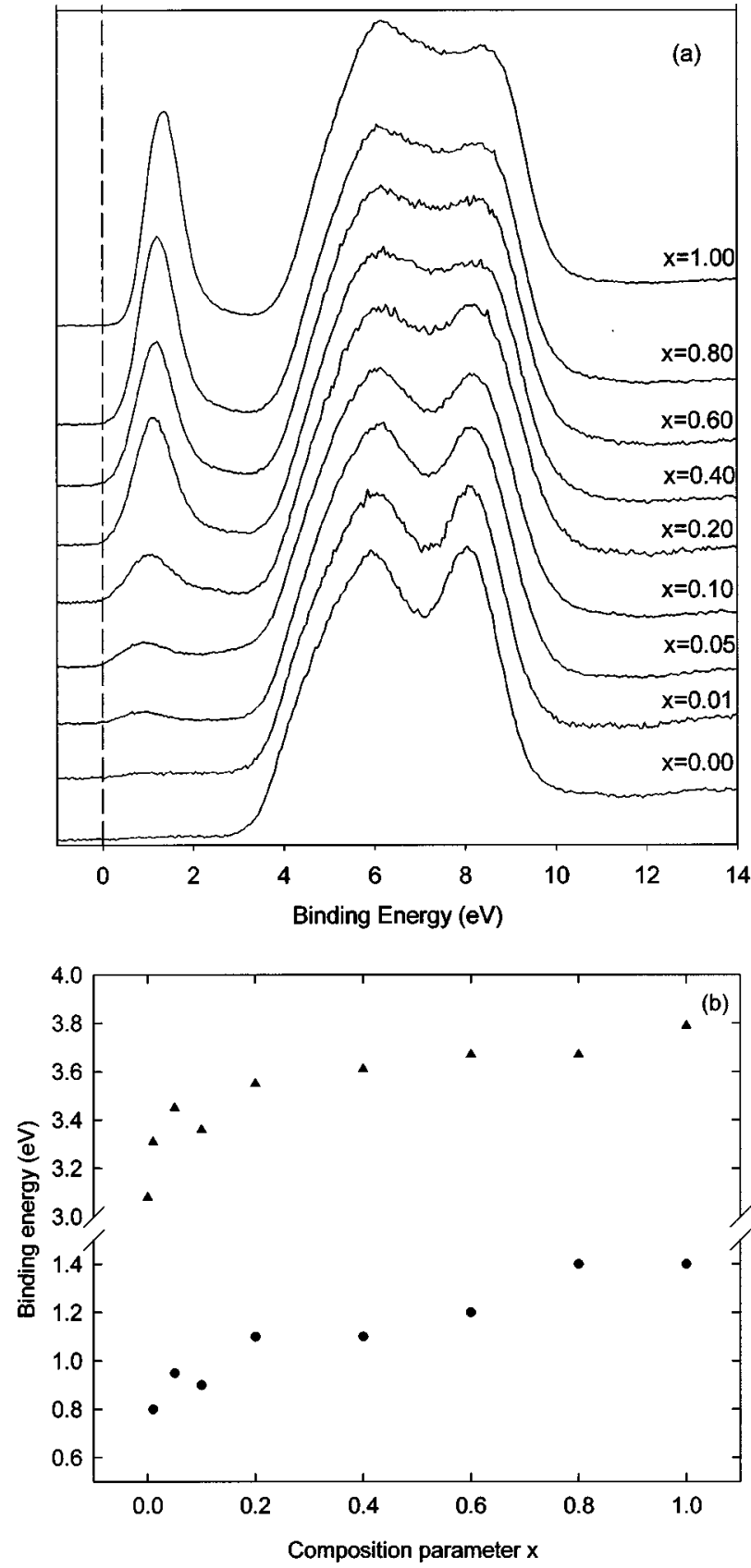

FIG. 3. (a) Valence-band x-ray photoemission spectra of $\mathrm{Ti}_{1-x} \mathrm{Nb}_{x} \mathrm{O}_{2}$ ceramics for the differing $x$ values indicated. Binding energies are relative to the Fermi energy of a calibrant silver foil. (b) Binding energy of the peak maximum for $\mathrm{Ti} 3 d$ or $\mathrm{Nb} 4 d$ photoemission feature in the bulk band gap (solid circles) and binding energy of the $\mathrm{O} 2 p$ valence-band onset (solid triangles) for $\mathrm{Ti}_{1-x} \mathrm{Nb}_{x} \mathrm{O}_{2}$ ceramics as a function of the composition parameter $x$.

spectral profile is further complicated by the buildup of intensity to the high-binding-energy side of the doublet due to $\mathrm{Nb} 3 s$ states.

The evolution of photoemission structure at low doping levels is further illustrated by curve fits to the spectral profiles in Fig. 6. At the lowest 1\% doping level [Fig. 6(a)] the position of the $\mathrm{Nb} 3 d$ doublet corresponds to that found in $\mathrm{Nb}_{2} \mathrm{O}_{5}$ so that the substitutional $\mathrm{Nb}$ is incorporated within the $\mathrm{TiO}_{2}$ lattice as $\mathrm{Nb}(\mathrm{V})$. By contrast, even at this very low doping level there is a marked growth in intensity of the

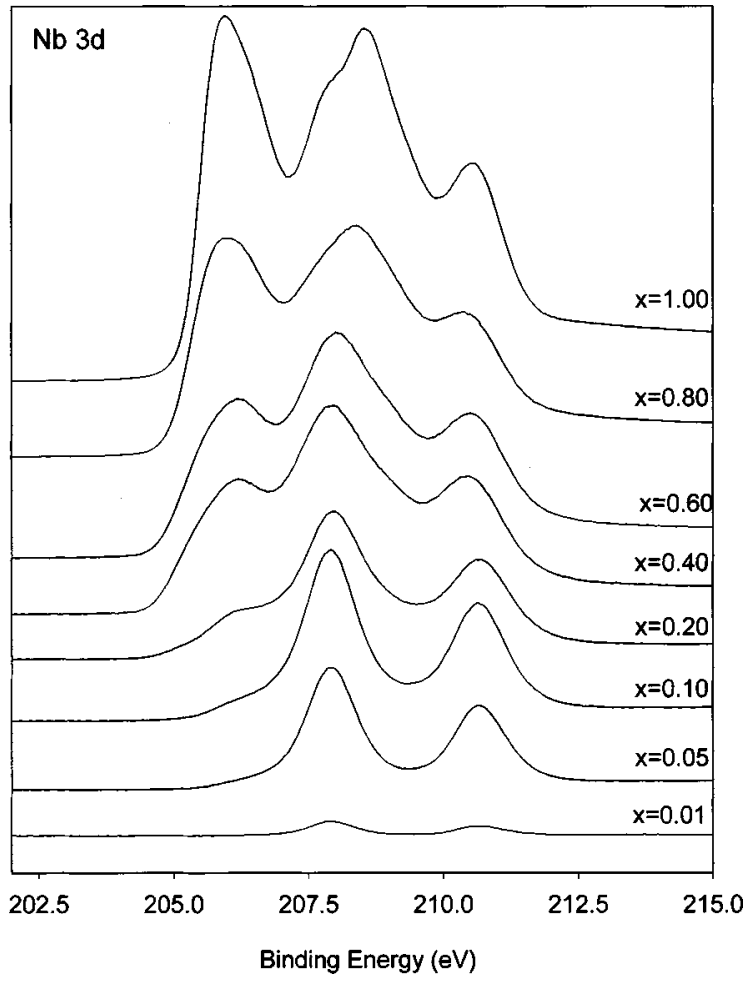

FIG. 4. $\mathrm{Nb} 3 d$ core-level $\mathrm{x}$-ray photoemission spectra of $\mathrm{Ti}_{1-x} \mathrm{Nb}_{x} \mathrm{O}_{2}$ ceramics for the differing $x$ values indicated. Binding energies are relative to the Fermi energy of a calibrant silver foil. The absolute intensity is scaled relative to the intensity of the $\mathrm{O} 1 \mathrm{~s}$ core level peak.

$\mathrm{Ti}(\mathrm{III})$ structure. Thus the extra electrons introduced by $\mathrm{Nb}$ become transferred to Ti sites. The core photoemission spectra of $\mathrm{Nb}$-doped $\mathrm{TiO}_{2}$ contrast with those of $\mathrm{V}$-doped $\mathrm{TiO}_{2}$, which clearly show that the electron introduced by doping are trapped on $\mathrm{V}$ sites. ${ }^{51}$ At $10 \%$ doping level [Fig. 6(b)], there is further growth in the intensity of the the Ti(III) structure but also development on shoulders on the low-bindingenergy side of the $\mathrm{Nb} 3 d$ doublet. These are due to $\mathrm{Nb}$ (IV).

The curve-fitting analysis may be used to quantify the distribution of excess charge between $\mathrm{Ti}$ and $\mathrm{Nb}$ and the degree of compensation at the surfaces of our UHV annealed ceramic samples. As shown in Fig. 7, the apparent surface concentration ratio $[\mathrm{Nb}] /\{[\mathrm{Nb}]+[\mathrm{Ti}]\}$ derived from crosssection-corrected $\mathrm{Nb} 3 d$ and Ti $2 p$ intensities increases with increasing doping level but is always higher than expected from the bulk doping level. This implies pronounced surface segregation of $\mathrm{Nb}$ in these samples, a not unexpected result given the larger size of $\mathrm{Nb}$ as compared with Ti. Size mismatch is one of the dominant thermodynamic driving forces for surface segregation in doped oxide systems. ${ }^{52}$ In addition, the summed $\mathrm{Ti}$ (III) and $\mathrm{Nb}$ (IV) contribution to the overall cation core signal intensity is compared with the $\mathrm{Nb}$ content probed by XPS. In the absence of any compensation of the $\mathrm{Nb}$ doping, these two quantities should coincide. However as evident in Fig. 7 there is significant (but not complete) compensation for doping levels up to $20 \%$. It was not possible to extend this analysis beyond low doping levels owing to the complexity in the line shapes at higher doping level (arising in part from overlap of $\mathrm{Nb} 3 s$ structure with Ti $2 p$ structure) and the complete breakdown in the relationship between the 


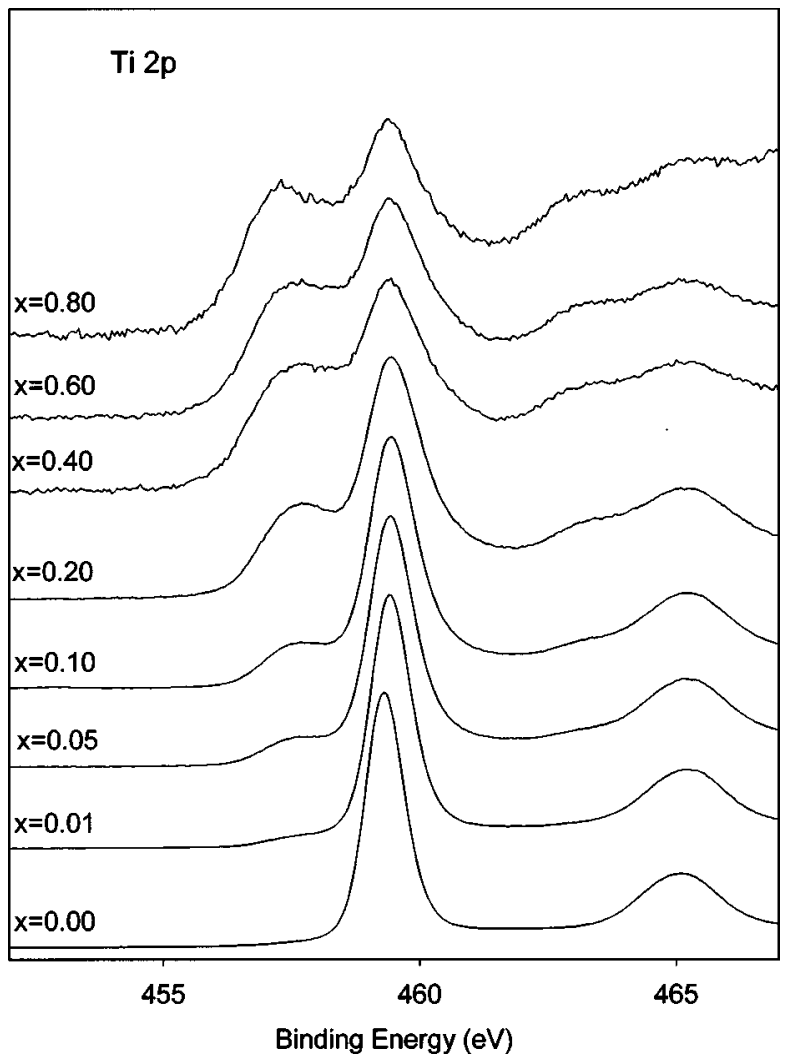

FIG. 5. Ti $2 p$ core-level $\mathrm{x}$-ray photoemission spectra of $\mathrm{Ti}_{1-x} \mathrm{Nb}_{x} \mathrm{O}_{2}$ ceramics for the differing $x$ values indicated. Binding energies are relative to the Fermi energy of a calibrant silver foil. The Ti $2 p_{3 / 2}$ peak maximum is scaled to the same intensity in each spectrum.

final-state $d^{0}: d^{1}$ intensity ratio and the initial-state $d$-electron count for $\mathrm{NbO}_{2}$. The charge distribution between $\mathrm{Ti}$ and $\mathrm{Nb}$ sites is also plotted in Fig. 7, revealing a significant transfer of charge back from $\mathrm{Ti}$ to $\mathrm{Nb}$ by the time $20 \%$ bulk doping has been achieved.

\section{Resonance photoemission of band-gap states of $\mathrm{Ti}_{0.9} \mathrm{Nb}_{0.1} \mathrm{O}_{2}$}

Constant-initial-state photoemission profiles taken at $1 \mathrm{eV}$ binding energy for $\mathrm{Ti}_{0.9} \mathrm{Nb}_{0.1} \mathrm{O}_{2}$, oxygen-deficient $\mathrm{TiO}_{2-x}$, and $\mathrm{NbO}_{2}$ are shown in Fig. 8. The photon energy range between 30 and $50 \mathrm{eV}$ embraces the $\mathrm{Ti} 3 p$ and $\mathrm{Nb} 4 p$ core thresholds. The profile for $\mathrm{TiO}_{2-x}$ is reproduced from Ref. 53 and displays the well-known Fano line shape. This arises from interference between the direct photoemission channel,

$$
\operatorname{Ti}\left(3 p^{6} 3 d^{1}\right)+h \nu \rightarrow \operatorname{Ti}\left(3 p^{6} 3 d^{0}\right)+e,
$$

and a resonant channel involving $3 p$ photoexcitation followed by super-Coster-Kronig decay:

$$
\begin{gathered}
\operatorname{Ti}\left(3 p^{6} 3 d^{1}\right)+h \nu \rightarrow \operatorname{Ti}\left(3 p^{5} 3 d^{2}\right)^{*}, \\
\operatorname{Ti}\left(3 p^{5} 3 d^{2}\right)^{*} \rightarrow \operatorname{Ti}\left(3 p^{6} 3 d^{0}\right)+e .
\end{gathered}
$$

The Ti $3 p$ core binding energy is about $37 \mathrm{eV}$, but the resonance edge reaches half its maximum height at a higher photon energy around $43.2 \mathrm{eV}$.
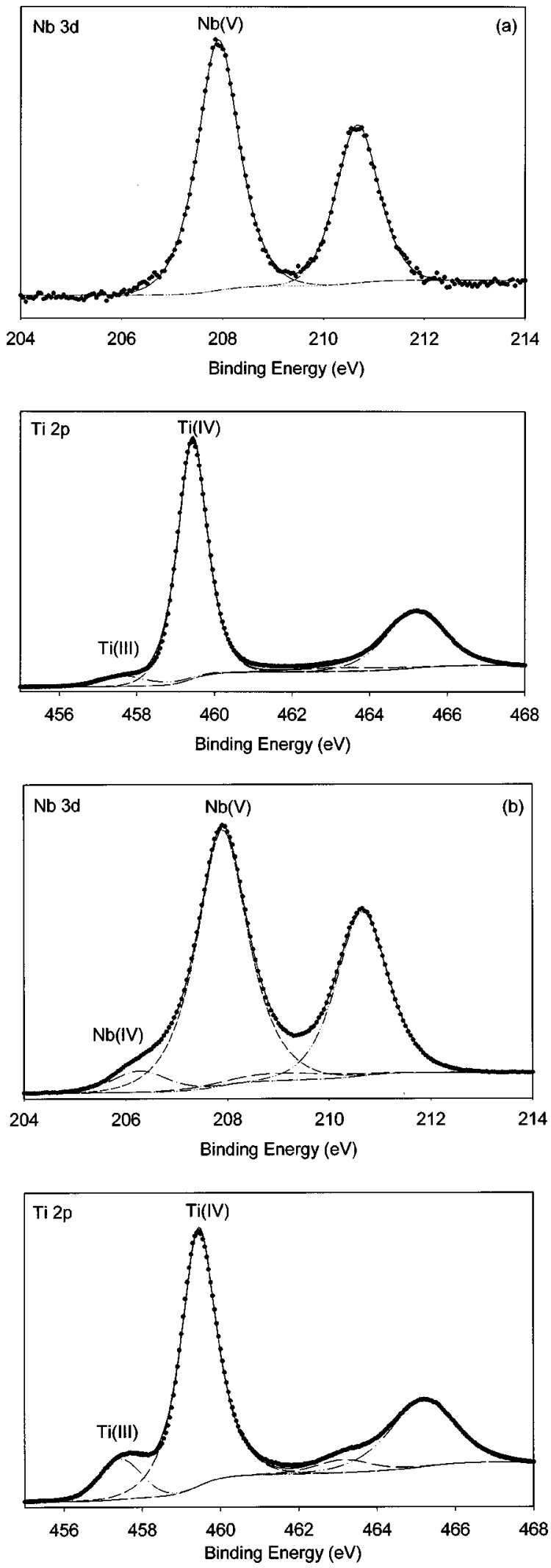

FIG. 6. (a) Curve fit to the $\mathrm{Nb} 3 d$ and $\mathrm{Ti} 2 p$ core-level $\mathrm{x}$-ray photoemission spectra of $\mathrm{Ti}_{0.99} \mathrm{Nb}_{0.01} \mathrm{O}_{2}$ (1\% Nb-doped $\left.\mathrm{TiO}_{2}\right)$. (b) Curve fit to the $\mathrm{Nb} 3 d$ and $\mathrm{Ti} 2 p$ core-level $\mathrm{x}$-ray photoemission spectra of $\mathrm{Ti}_{0.90} \mathrm{Nb}_{0.10} \mathrm{O}_{2}\left(10 \% \mathrm{Nb}\right.$-doped $\left.\mathrm{TiO}_{2}\right)$. The dots are experimental data points and the solid lines are best fits to these data with an addition of a Shirley background and individual Voigt functions for $\mathrm{Nb}(\mathrm{V}), \mathrm{Nb}(\mathrm{IV}), \mathrm{Ti}(\mathrm{IV})$, and $\mathrm{Ti}(\mathrm{III})$ final states. 


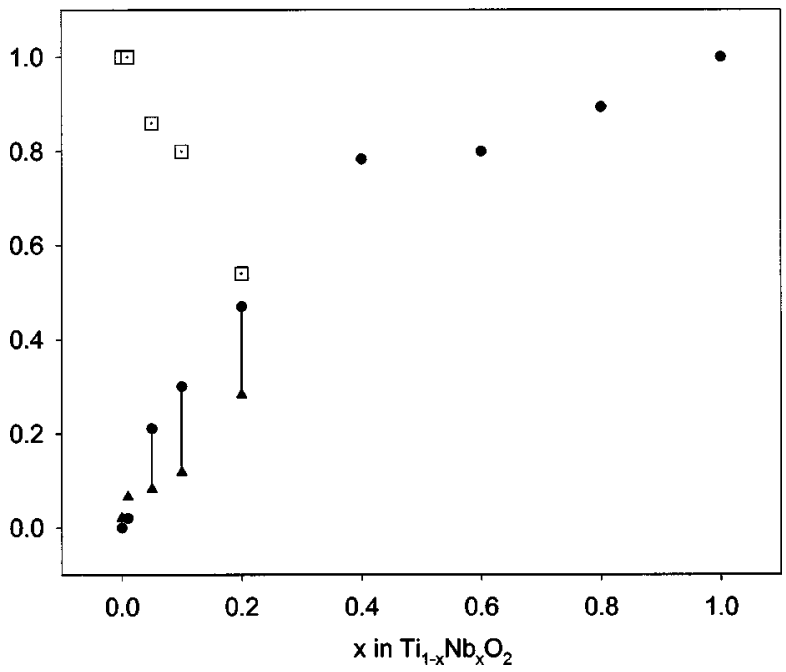

FIG. 7. Solid circles: the effective $\mathrm{Nb}$ cation site occupancy derived from core XPS. Solid triangles: the total fraction of cations in a reduced state. The solid lines linking the triangles to the circles indicate the degree of compensation $1-[n] /[\mathrm{Nb}]$. Open squares: the distribution of the $n$-type carriers between $\mathrm{Ti}$ and $\mathrm{Nb}$ sites, i.e., $[\mathrm{Ti}(\mathrm{III})] /[\mathrm{Nb}(\mathrm{V})]$.

The $\mathrm{Nb} 4 p$ core binding energy of $\mathrm{NbO}_{2}$ is at the lower value $35 \mathrm{eV}$ and the resonance profile now involves the interference between

$$
\mathrm{Nb}\left(4 p^{6} 4 d^{1}\right)+h \nu \rightarrow \operatorname{Ti}\left(4 p^{6} 4 d^{0}\right)+e
$$

and

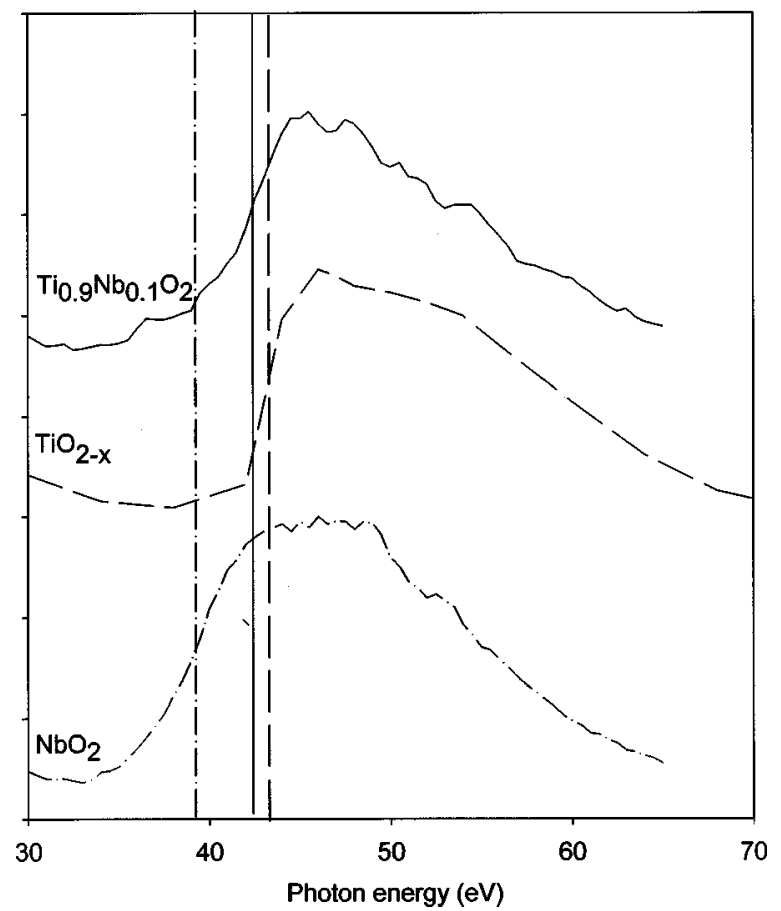

FIG. 8. Constant-initial-state resonant photoemission profiles taken at $1 \mathrm{eV}$ binding energy for $\mathrm{Ti}_{0.90} \mathrm{Nb}_{0.10} \mathrm{O}_{2}$ (solid curve), $\mathrm{TiO}_{2-x}$ (dashed curve), and $\mathrm{NbO}_{2}$ (dash-dotted curve). The vertical lines identify the energy where the resonance edges reach half of maximum intensity.
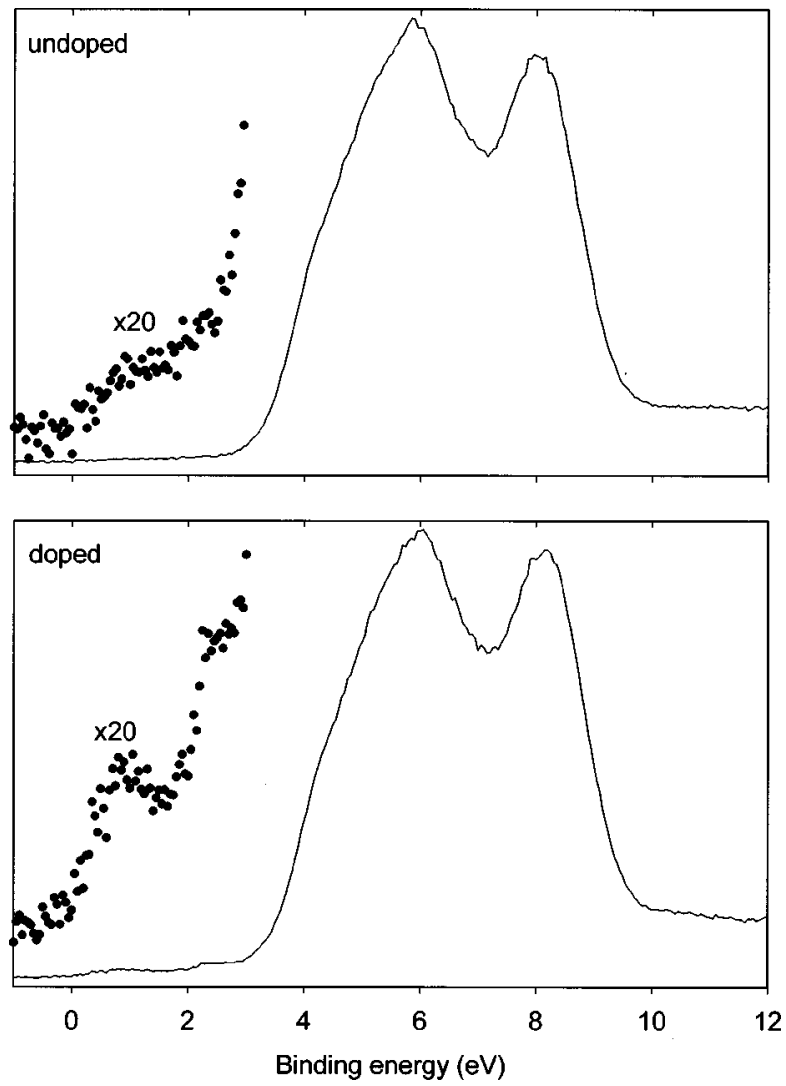

FIG. 9. Valence-band XPS of undoped $\mathrm{TiO}_{2}(110)$ (upper spectrum) and $\mathrm{TiO}_{2}(110)$ doped with $\mathrm{Nb}$ by diffusion from $1 \% \mathrm{Nb}$ doped $\mathrm{TiO}_{2}$ powder (lower spectrum).

$$
\begin{aligned}
& \mathrm{Nb}\left(4 p^{6} 4 d^{1}\right)+h \nu \rightarrow \mathrm{Nb}\left(4 p^{5} 4 d^{2}\right)^{*}, \\
& \mathrm{Nb}\left(4 p^{5} 4 d^{2}\right)^{*} \rightarrow \mathrm{Nb}\left(4 p^{6} 4 d^{0}\right)+e .
\end{aligned}
$$

The resonance edge for $\mathrm{NbO}_{2}$ reaches half maximum height at $39.2 \mathrm{eV}$ photon energy. The resonance profile for the doped system is characterized by a resonance edge reaching half-maximum height at $42.5 \mathrm{eV}$ photon energy. As is clear from Fig. 8 this is much closer to the value for $\mathrm{TiO}_{2-x}$ than for $\mathrm{NbO}_{2}$. Resonance photoemission thus reinforces the conclusion that at low doping level the electrons associated with the band-gap state reside mainly on Ti. Again the results of the present study contrast with those for $\mathrm{V}$-doped $\mathrm{TiO}_{2},{ }^{54}$ where the resonance edge of the dopant-induced gap peak coincides with that for $\mathrm{VO}_{2}$ (Ref. 55) rather than $\mathrm{TiO}_{2-x}$ (Ref. 53). Thus resonant photoemission confirms the conclusion from core photoemission that the trapping site for $n$-type donor electrons differs between the two dopant systems.

\section{X-ray photoemission, STM, and LEED observations on diffusion-doped $\mathrm{TiO}_{2}$ single crystals}

Both (110)- and (210)-oriented ${ }^{56}$ single crystals of $\mathrm{TiO}_{2}$ diffusionally doped from $1 \% \mathrm{Nb}$-doped rutile were studied by high-resolution $\mathrm{x}$-ray photoemission, with essentially similar results. As shown in Fig. 9, Nb doping leads to enhanced photoemission intensity in the rutile band gap. This is associated with increased intensity of the low-bindingenergy shoulder associated with Ti(III) in core-level photoemission (Fig. 10). In this case the increase in the [Ti(III)]/ 

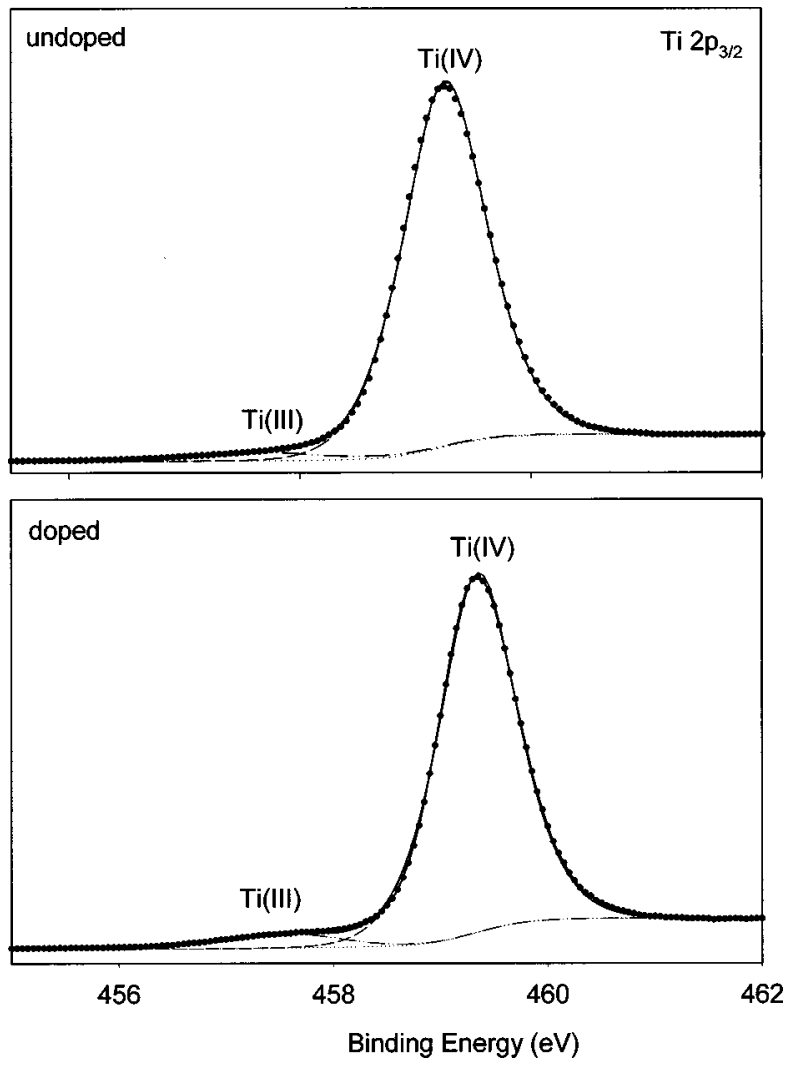

FIG. 10. Ti $2 p_{3 / 2}$ core XPS of undoped $\mathrm{TiO}_{2}(110)$ (upper spectrum) and $\mathrm{TiO}_{2}(110)$ doped with $\mathrm{Nb}$ by diffusion from $1 \% \mathrm{Nb}$ doped $\mathrm{TiO}_{2}$ powder (lower spectrum).

[Ti(total)] ratio from 0.035 to 0.057 is close to the $\mathrm{Nb}$ doping level $[\mathrm{Nb}] /\{[\mathrm{Nb}]+[\mathrm{Ti}($ total $)]\}=0.016$ inferred from the $\mathrm{Nb} 3 d$ intensity. Moreover, as with the ceramic samples, the $\mathrm{Nb}$ core line is characteristic of $\mathrm{Nb}(\mathrm{V})$. Thus the behavior of single-crystal $\mathrm{Nb}$-doped $\mathrm{TiO}_{2}$ is in line with that found for ceramic samples at comparably low doping levels.

Typical LEED patterns from a (110)-oriented Nb-doped crystal are shown in Fig. 11. There is no indication of dopant ordering and the pattern corresponds to the well-known (1 $\times 1)$ reconstruction for $\mathrm{TiO}_{2}(110)$. An STM image from the doped crystal is shown in Fig. 12. This was obtained at +2.0 $\mathrm{V}$ sample bias and $1 \mathrm{nA}$ tunnel current, i.e., under conditions where the STM imaging probes contours of empty state charge density. The image is dominated by bright rows running along the [001] direction, as observed in many previous studies. ${ }^{57-62}$ In addition the image contains a number of "extra bright" clusters. Some of these are resolved into a square of four "extra bright" spots appearing on the bright rows.

The electrostatically stable ${ }^{63}(1 \times 1)$ reconstruction of $\mathrm{TiO}_{2}(110)$ involves two Ti ions per surface unit cell. Half of the surface $\mathrm{Ti}$ ions are coordinated by only five oxygen ions. However, rows of bridging oxygen ions running along the [001] direction that comprise the outer $\{\mathrm{O}\}$ layer lie above the surface $\mathrm{Ti}_{2} \mathrm{O}_{2}$ plane and complete the sixfold coordination of the remaining surface Ti ions. STM images of $\mathrm{TiO}_{2}(110)$ obtained at positive sample bias contain bright rows aligned parallel to [001]. The rows in STM could correspond either to the bridging oxygen rows or to the rows of bare fivefold-coordinated $\mathrm{Ti}$ ions. On the basis of experiments involving adsorption of formate ${ }^{64}$ or chlorine ${ }^{65}$ the

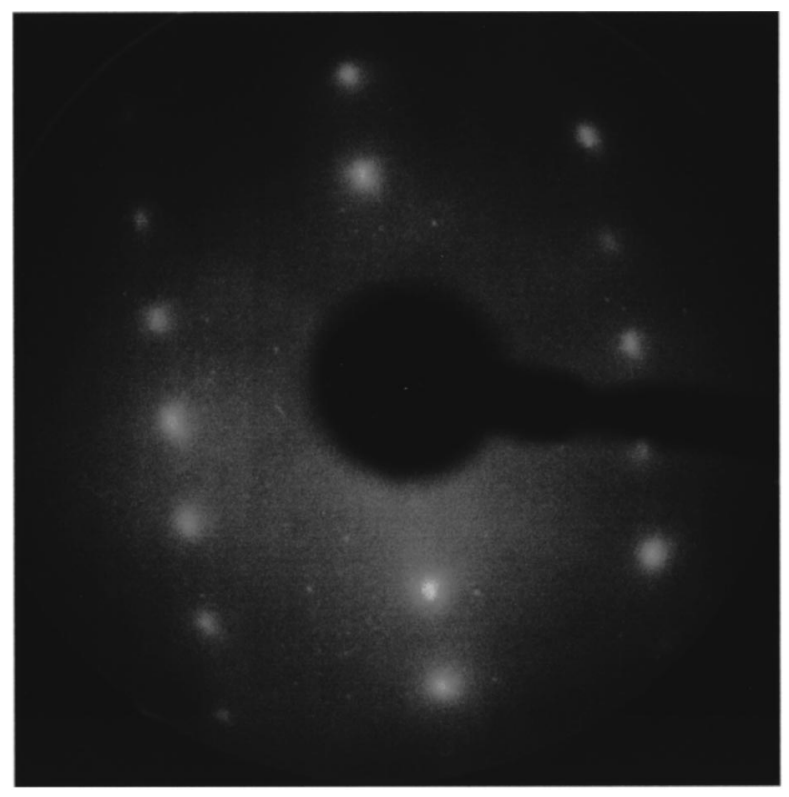

FIG. 11. LEED pattern of $\mathrm{Nb}$-doped $\mathrm{TiO}_{2}(110)$ taken at $95 \mathrm{eV}$ beam energy.

latter interpretation is now favored. Density-functional calculations reveal that contours of empty-state charge-density bend outward above $\mathrm{Ti}$ positions more strongly than above $\mathrm{O}$ positions, even though the bridging $\mathrm{O}$ ions are uppermost. ${ }^{66}$ Thus electronic structure effects dominate purely structural effects in determining the form of STM images.

Within this interpretation of STM images for $\mathrm{TiO}_{2}$ itself, we then associate each "extra bright" cluster with Ti ions surrounding a single $\mathrm{Nb}$ dopant atom at the surface. The $\mathrm{Nb}(\mathrm{V})$ dopant species are presumed to occupy sites between the bright rows. Charge transfer to the surrounding Ti ions then yields gray-scale contrast in the STM images: the en-

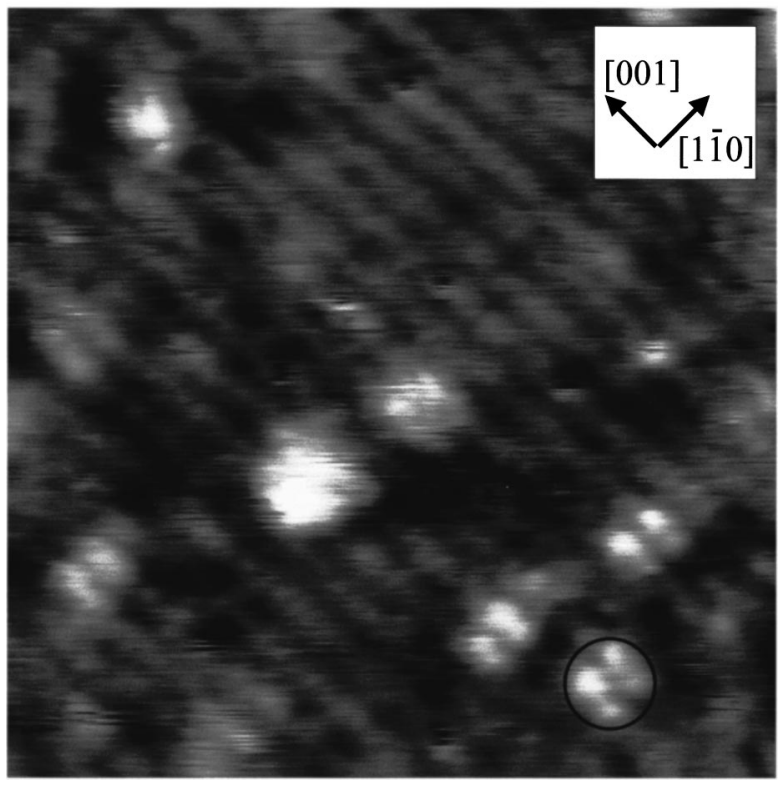

FIG. 12. $100 \AA \times 100 \AA$ STM image of Nb-doped $\mathrm{TiO}_{2}(110)$ acquired at $1 \mathrm{nA}$ tunnel current and $+2.0 \mathrm{~V}$ sample bias. A single bright spot cluster (which is believed to correspond to a Nb-dopant atom) is highlighted with a circle. 
hanced brightness is most easily understood in terms of increased local conductivity. The separation of the spots within the cluster of about $6 \AA$ along the [001] direction is somewhat surprising as this distance is twice the separation between $\mathrm{Ti}$ ions along [001]. If the $\mathrm{Nb}$ ions occupied sixfoldcoordinated sites in the surface ionic layer we would expect symmetric delocalization of charge to either side along the [001] direction, thus giving clusters with a spot separation of $3 \AA$ (or $9 \AA$ if the delocalization extended over three surface unit cells). One simple model that accounts for delocalization over two cells involves preferential incorporation of dopant atoms within the subsurface $\mathrm{Ti}_{2} \mathrm{O}_{2}$ layer in the $\mathrm{Ti}$ sites under the bridging oxygen rows. The Ti sites in this layer are displaced by half a unit cell along the [001] direction relative to Ti sites in the topmost $\mathrm{Ti}_{2} \mathrm{O}_{2}$ layer. Symmetric delocalization of charge onto adjacent $\mathrm{Ti}$ ions including those in the topmost $\mathrm{Ti}_{2} \mathrm{O}_{2}$ layer would naturally encompass two surface unit cells.

The STM image of Fig. 11 has a total area of $10^{4} \AA^{2}$ and includes 1040 cation sites. Given that the surface Nb concentration probed by XPS is $1.1 \%$, we expect to see about 11 clusters in this image. We used an automated image analysis program to count bright clusters with dimensions of (6 $\pm 1)^{2} \AA^{2}$ in a large number of images encompassing a total area of $2.76 \times 10^{7} \AA^{2}$, i.e., 276 times the area depicted in Fig. 12. We find the mean number of clusters per $10^{4} \AA^{2}$ is 7 . This is somewhat lower than expected from XPS, although of course XPS measures the average $\mathrm{Nb}$ concentration over a range of atomic layers within the effective probing depth of the technique and not simply the concentration in a single atomic layer.

\section{DISCUSSION}

\section{A. Comparison with previous experimental work}

The as-prepared $\mathrm{Nb}$-doped $\mathrm{TiO}_{2}$ ceramics studied in the present work were all intensely blue or blue-black materials, while the diffusionally doped single crystals displayed a deep blue coloration similar to that found for $\mathrm{TiO}_{2}$ crystals reduced by annealing in hydrogen. This accords with previous work which found a band at $1 \mathrm{eV}$ in diffuse reflectance spectra whose intensity increased with increasing doping $\mathrm{Nb}$ doping level ${ }^{67}$ Undoped $\mathrm{TiO}_{2}$ ceramics or crystals developed a much less intense coloration as a result of annealing in UHV and displayed essentially no color change after annealing is sealed quartz tubes. These simple observations suggest that doping is associated with the introduction of new electronic states into the host band gap, giving rise to new optical excitation processes in the visible region. In accord with this expectation distinct photoemission features are found in the bulk band gap and there is a sensible evolution of electronic properties between the $\mathrm{TiO}_{2}$ and $\mathrm{NbO}_{2}$ end members.

The present findings are thus at variance with work on Nb-doped $\mathrm{TiO}_{2}$ films grown by deposition of $\mathrm{Ti}$ and $\mathrm{Nb}$ metal in an oxygen radical plasma. In that work the epitaxial material was formulated as $\mathrm{Ti}_{1-x} \mathrm{Nb}_{x} \mathrm{O}_{2}$, but no photoemission features were found in the host band gap. ${ }^{28,29}$ Moreover, the films were reported to be optically transparent in the visible region and exhibited poor electrical conductivity. It is therefore interesting to consider the likely degree of compensation under the conditions of MBE growth. The bulk defect chemistry of $\mathrm{Nb}$-doped $\mathrm{TiO}_{2}$ was investigated in detail by Tani and Baumi, ${ }^{18}$ who considered the dependence on oxygen partial pressure of the titanium interstitial concentration $\left[\mathrm{Ti}_{i}^{4}\right]$, the titanium cation vacancy concentration $\left[\mathrm{V}_{\mathrm{Ti}}^{4}\right]$ and the $n$-type and $p$-type carrier concentrations, designated $n$ and $p$. The interrelationships between these quantities are governed by three quasichemical equilibrium constants:

$$
\begin{gathered}
K_{1}=\left[\mathrm{Ti}_{i}^{4}\right] n^{4} P\left(\mathrm{O}_{2}\right), \\
K_{2}=\left[\mathrm{V}_{\mathrm{Ti}}^{4^{\prime}}\right] p^{4} / P\left(\mathrm{O}_{2}\right), \\
K_{3}=n p .
\end{gathered}
$$

Charge balance requires that

$$
\left[\mathrm{Nb}_{\mathrm{Ti}}\right]+4\left[\mathrm{Ti}_{i}^{4}\right]+p=n+4\left[\mathrm{~V}_{\mathrm{Ti}}^{4^{\prime}}\right],
$$

where $\left[\mathrm{Nb}_{\mathrm{Ti}}\right]$ is the substitutional Nb-doping concentration. The $n$-type carrier concentration is in turn determined by the nonlinear equation:

$$
4 K_{1} /\left\{n^{4} P\left(\mathrm{O}_{2}\right)\right\}+\left[\mathrm{Nb}_{\mathrm{Ti}}\right]=n+4 K_{2} K_{3}^{-4} n^{4} P\left(\mathrm{O}_{2}\right) .
$$

Values for the constants $K_{1}$ and the product $K_{2} K_{3}^{-4}$ were determined from conductivity measurements taken in the range up to $1623 \mathrm{~K}$. The term $4 K_{1} /\left\{n^{4} P\left(\mathrm{O}_{2}\right)\right\}$ is only important at exceedingly low oxygen partial pressures or low niobium-doping levels and accounts for the introduction of donor states by completely ionized titanium intersitials. Thus in the regime of relevance to oxygen plasma assisted MBE growth $n$ depends on the simplified relationship:

$$
4 K_{2} K_{3}^{-4} n^{4} p\left(\mathrm{O}_{2}\right)+n-\left[\mathrm{Nb}_{\mathrm{Ti}}\right]=0 .
$$

At sufficiently low oxygen partial pressure $n=\left[\mathrm{Nb}_{\mathrm{Ti}}\right]$, and the $\mathrm{Nb}$ doping is uncompensated. However, at higher oxygen partial pressure the concentration of compensating cation vacancies increases and the carrier concentration drops off with oxygen partial pressure essentially according to the relationship

$$
n=\left\{\left[\mathrm{Nb}_{\mathrm{Ti}}\right] K_{3}^{4} K_{2}^{-1} / 4 p\left(\mathrm{O}_{2}\right)\right\}^{1 / 4} .
$$

Making a logarithmic extrapolation versus inverse temperature for the values for $K_{2} K_{3}^{-4}$ tabulated by Tani and Baumi we estimate that at $873 \mathrm{~K}$ (the temperature of MBE growth), $K_{2} K_{3}^{-4}=10^{-49}$. It is then possible to solve Eq. (5) for various doping levels and oxygen partial pressures. Taking specific values relevant to the MBE growth conditions of $p\left(\mathrm{O}_{2}\right)=5 \times 10^{-5}$ torr (which is equivalent to 6.6 $\times 10^{-8} \mathrm{~atm}$ ) and $\left[\mathrm{Nb}_{\mathrm{Ti}}\right]=3.2 \times 10^{21} \mathrm{~cm}^{-3}$ (corresponding to occupation of $10 \%$ of $\mathrm{Ti}$ sites by $\mathrm{Nb}$ ), we obtain $n=1.87$ $\times 10^{19} \mathrm{~cm}^{-3}$. Thus the concentration of occupied donor states is only $0.58 \%$ of the $\mathrm{Nb}$-doping level and the remaining $99.42 \%$ of the $\mathrm{Nb}$ doping needs to be compensated in some way. This would require vacancies on $2.48 \%$ of the cation sites or (less likely) oxygen interstitials. The $n$-type 
carrier concentration is the same as would be found in uncompensated $\mathrm{Ti}_{0.9994} \mathrm{Nb}_{0.0006} \mathrm{O}_{2}$ and would be difficult to observe in photoemission. This simple calculation assumes that the effective oxygen fugacity in the plasma corresponds simply to the background oxygen pressure. In practice the plasma is likely to be even more strongly oxidizing so that the degree of compensation could well be greater. Thus under the conditions of MBE growth most of the $\mathrm{Nb}$ dopant and the host $\mathrm{Ti}$ should be in their maximal oxidation state, i.e., we have $\mathrm{Ti}(\mathrm{IV})$ and $\mathrm{Nb}(\mathrm{V})$. Interestingly it appears that the stability range for the $\mathrm{Nb}$-doped rutile phase under the oxidising conditions of $\mathrm{MBE}$ growth is much greater than for bulk material. When $\mathrm{Ti}_{1-x} \mathrm{Nb}_{x} \mathrm{O}_{2}$ is oxidized the phase diagram for the $\mathrm{TiO}_{2} / \mathrm{Nb}_{2} \mathrm{O}_{5}$ system ${ }^{68}$ indicates that the monoclinic phase $\mathrm{TiNb}_{2} \mathrm{O}_{7}$ exsolves ${ }^{69}$ when the $\mathrm{Nb}$-doping level exceeds about $8 \%$. In the MBE experiments compensated $\mathrm{Nb}$ can be incorporated within the rutile phase for $\mathrm{TiO}_{2}$ doping levels up to $40 \%$.

We need next to consider whether the conclusion that $\mathrm{Nb}$ is oxidized to $\mathrm{Nb}(\mathrm{V})$ in the oxygen plasma can be reconciled with the $\mathrm{Nb} 3 d_{5 / 2}$ binding energy of $206.96 \mathrm{eV}$ reported for the doped films. ${ }^{28,29}$ Due to charging problems absolute binding energies could not be obtained. Instead a tabulated value $^{70}$ of $458.7 \mathrm{eV}$ for the Ti $2 p_{3 / 2}$ binding energy in $\mathrm{TiO}_{2}$ was used as reference and the experimental $\mathrm{Nb} 3 d_{5 / 2}$ binding energy was shifted accordingly. In the present work we find the Ti $2 p_{3 / 2}$ binding energy for $\mathrm{TiO}_{2}$ to be 459.30 $\pm 0.05 \mathrm{eV}$ and the $\mathrm{Nb} 3 d_{5 / 2}$ binding energy of $\mathrm{Nb}_{2} \mathrm{O}_{5}$ to be $207.80 \pm 0.05 \mathrm{eV}$. Thus the difference between the Ti $2 p_{3 / 2}$ and $\mathrm{Nb} 3 d_{5 / 2}$ binding energies of $(458.7-206.96) \mathrm{eV}$ $=251.74 \mathrm{eV}$ found in the earlier work compares with a value of $(459.30-207.80) \mathrm{eV}=251.5 \mathrm{eV}$ for the difference between $\mathrm{Ti}(\mathrm{IV})$ in $\mathrm{TiO}_{2}$ and $\mathrm{Nb}(\mathrm{V})$ in $\mathrm{Nb}_{2} \mathrm{O}_{5}$ found in the present work. The discrepancy of $0.24 \mathrm{eV}$ is barely significant and in further reduced to $0.09 \mathrm{eV}$ if we use a more appropriate $\mathrm{Ti}(\mathrm{IV}) 2 p_{3 / 2}$ binding energy of 459.45 $\pm 0.05 \mathrm{eV}$ for $\mathrm{Ti}$ in $\mathrm{Nb}$-doped $\mathrm{TiO}_{2}$ with doping levels in excess of $5 \%$.

The extreme susceptibility of the $\mathrm{Nb}$-doped $\mathrm{TiO}_{2}$ system to compensation probably accounts for the discrepancy between the effective donor level to be inferred from our core photoemission measurements and the Nb-doping level. Thus again considering $10 \% \mathrm{Nb}$-doped material with $\left[\mathrm{Nb}_{\mathrm{Ti}}\right]=3.2$ $\times 10^{21} \mathrm{~cm}^{-3}$, the $n$-type donor level is reduced to $\left[\mathrm{Nb} \mathrm{Ti}_{\mathrm{Ti}}\right]$ $=1.6 \times 10^{21} \mathrm{~cm}^{-3}$ (i.e., there is $50 \%$ compensation) if the surface is equilibrated with an oxygen partial pressure of $4.6 \times 10^{-9}$ torr at $750^{\circ} \mathrm{C}$. This is well above the residual oxygen partial pressure in the vacuum systems we have used. However at $600{ }^{\circ} \mathrm{C}$, the critical pressure for $50 \%$ compensation is $4.6 \times 10^{-13}$ torr. We had no means of monitoring oxygen partial pressure at this low level and we cannot guarantee that the critical pressure is not exceeded. Thus even though the equilibrium degree of compensation at the annealing temperature of $750^{\circ} \mathrm{C}$ should ensure minimal compensation, if the surface equilibrates with the residual oxygen background pressure during cooling from $750{ }^{\circ} \mathrm{C}$, there may be significant (but not complete) compensation provided that sufficient ionic mobility is retained during sample cooling.

Finally we consider the present evidence for electron trapping on $\mathrm{Nb}$ rather than $\mathrm{Ti}$ sites at low doping levels in relation to previous experimental work. X-ray absorption mea- surements on both ceramic ${ }^{71,73}$ and thin-film ${ }^{72} \mathrm{TiO}_{2}-\mathrm{NbO}_{2}$ solid solutions are consistent with formulation of material with a low $\mathrm{Nb}$-doping level as $\mathrm{Ti}(\mathrm{IV})_{1-2 x} \mathrm{Ti}(\mathrm{III})_{x} \mathrm{Nb}(\mathrm{V})_{x} \mathrm{O}_{2}$ rather than $\mathrm{Ti}(\mathrm{IV})_{1-x} \mathrm{Nb}(\mathrm{IV})_{x} \mathrm{O}_{2}$. An analogous situation pertains for Ta doped material. ${ }^{74}$ This conclusion is further supported by ESR measurements. ${ }^{67}$

\section{B. Comparison with cluster calculations}

The valence-band XPS obtained in present work may be compared with density-of-states profiles for $\mathrm{Nb}$-doped $\mathrm{Ti}$ oxide clusters calculated by the density-functional method (DF) within the local density approximation as parametrized by Vosko, Wilck, and Nusair. ${ }^{75}$ The approach used has been described in detail elsewhere ${ }^{76}$ and involves elimination of unwanted dangling bond states with the use of pseudohydrogen saturators. This technique satisfactorily describes structural and electronic properties of oxides and their surfaces, ${ }^{77,78}$ including $\mathrm{TiO}_{2} \cdot{ }^{79,80}$ In the present case we consider a cluster introduced earlier ${ }^{76}$ containing $13 \mathrm{Ti}$ ions and $45 \mathrm{O}$ ions. This cluster contains a row of five of the fivefold coordinated $\mathrm{Ti}$ ions found on $\mathrm{TiO}_{2}(110)$ and two rows of four sixfold coordinated Ti ions on the same surface. The dangling bonds on $\mathrm{O}$ ions at the edges of the cluster that are unsaturated in comparison with $\mathrm{TiO}_{2}(110)$ are terminated with the appropriate number of hydrogen saturators. ${ }^{76}$ This procedure gives an electrostatically neutral cluster.

Density-of-states profiles were obtained by broadening the pattern of discrete cluster eigenvalues with a Lorentzian of $0.3 \mathrm{eV}$ half width. Partial densities of states for direct comparison with experiment were then obtained by decomposing each cluster level into its atomic contributions and weighting the contribution from different types of atomic orbital with one electron ionization cross sections appropriate to $\mathrm{Al} K \alpha$ radiation. $^{81}$ Only $\mathrm{O}$ atoms not carrying a saturator were included in this summation, and the weighting was adjusted to ensure that the two different sorts of $\mathrm{Ti}$ and $\mathrm{O}$ ion at the $\mathrm{TiO}_{2}(110)$ surface made equal contribution to the cross-section-weighted density of states.

Figure 13(a) shows cross-section-weighted densities of states for a pure Ti-containing cluster and for a cluster containing a single $\mathrm{Nb}$ ion. The latter corresponds to an effective $\mathrm{Nb}$ :Ti ratio of $1 / 9$ and should bear direct comparison with $\mathrm{X}$-ray photoemission data for $\mathrm{Nb}_{0.1} \mathrm{Ti}_{0.9} \mathrm{O}_{2}$. In agreement with the experimental observations a distinct new state appears above the $\mathrm{O} 2 p$ valence band as a result of $\mathrm{Nb}$ doping. The separation between this new level and the main O $2 p$ "valence band" is less than observed experimentally. This appears to be a general failure of local-density approximation (LDA) methods, which in both periodic and cluster calculations tend to underestimate band gaps. The atomic nature of the band-gap state is revealed in Fig. 13(b), which shows the $\mathrm{Nb} 4 d$ and Ti $3 d$ partial density of states for the Nb-doped cluster. The gap state has mixed $\mathrm{Ti} 3 d / \mathrm{Nb} 4 d$ character. Qualitatively this is in agreement with experiment, although the $\mathrm{Ti} 3 d / \mathrm{Nb} 4 d$ ratio is somewhat lower than implied by core-level spectra. The partial density-of-states plots also reveal that there is a pronounced $\mathrm{Ti} 3 d$ and $\mathrm{Nb} 4 d$ contribution to states in the valence band, which have predominant $\mathrm{O} 2 p$ character. This arises from strong $\mathrm{O} 2 p$-metal $d$ covalency. 

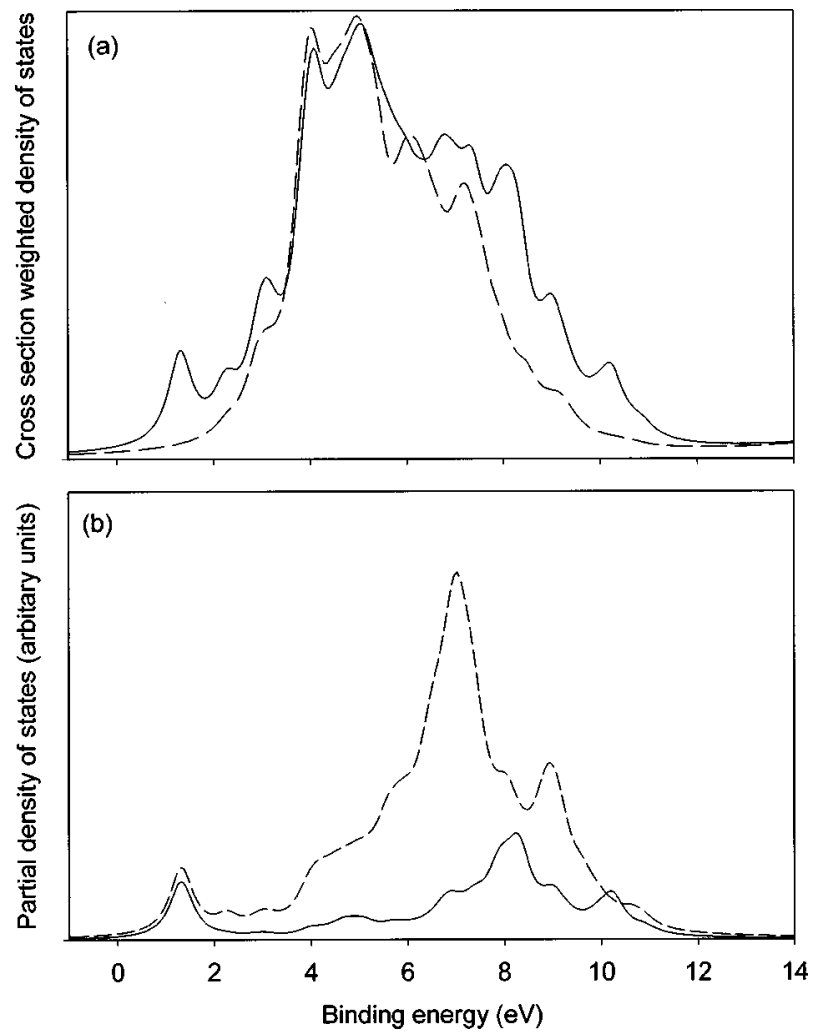

FIG. 13. (a) Cross-section-weighted density-of-states profiles for clusters designed to mimic $\mathrm{TiO}_{2}$. Solid line is for cluster containing only Ti cations. Dashed line is for cluster containing a single $\mathrm{Nb}$ ion. The density-of-states (DOS) profile for the latter corresponds essentially to $\mathrm{Ti}_{0.9} \mathrm{~N}_{0.1} \mathrm{O}_{2}$. (b) Unweighted partial densities of states for the Nb-doped cluster. Solid line is $\mathrm{Nb} 4 d$ partial DOSdashed line Ti $3 d$ partial DOS.

The relative metal $d$ contribution is strongest in the states toward the bottom of the valence band.

A striking feature of the cross-section-weighted density of states profiles is the increase in spectral weight toward the bottom of the valence band arising from $\mathrm{Nb}$ doping. This arises from the metal oxygen hybridization discussed above and the fact that the one electron cross section for ionization of $\mathrm{Nb} 4 d$ states $\left(\sigma=8.7 \times 10^{-4} \mathrm{Mb}\right)$ is at least an order of magnitude larger than for ionization of $\mathrm{Ti} 3 d(\sigma=8.5$ $\left.\times 10^{-5} \mathrm{Mb}\right)$ or O $2 p\left(\sigma=6.0 \times 10^{-5} \mathrm{Mb}\right)$ states. ${ }^{81}$ The consequences of this effect are further explored in Fig. 14 where the theoretical photoemission difference spectrum between the $\mathrm{Nb}$-doped and the undoped cluster are compared with the experimental difference spectrum between $\mathrm{Nb}_{0.1} \mathrm{Ti}_{0.9} \mathrm{O}_{2}$ and undoped $\mathrm{TiO}_{2}$. The latter reveals a pronounced increase in intensity across the $\mathrm{O} 2 p$ band as well as growth of the gap peak. It should be emphasised that the increased intensity in the $\mathrm{O} 2 p$ valence band does not arise from the introduction of new states into this region but merely from a change in the atomic character of the states.

\section{CONCLUDING REMARKS}

Valence-band photoemission spectra of Nb-doped $\mathrm{TiO}_{2}$ reveal a new state in the band gap of the rutile host material whose intensity increases with increasing doping level. Core-level spectroscopy and resonant photoemission demon-

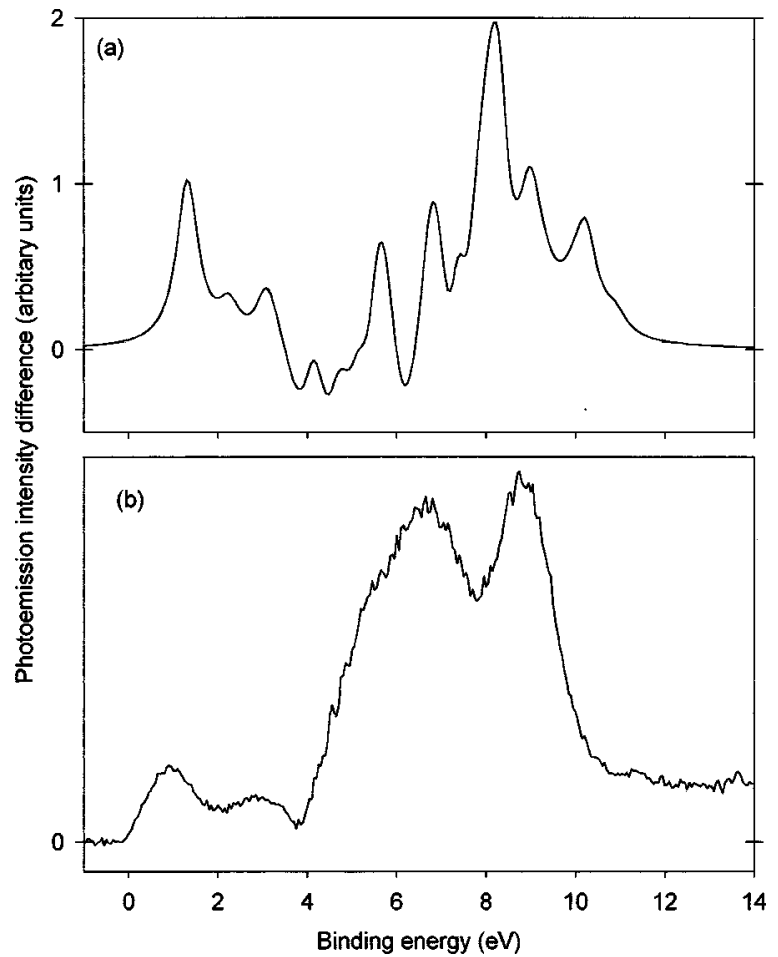

FIG. 14. (a) Theoretical photoemission difference spectrum between the Nb-doped and undoped cluster. (b) Experimental x-ray photoemission difference spectrum between $\mathrm{Ti}_{0.9} \mathrm{~N}_{0.1} \mathrm{O}_{2}$ and $\mathrm{TiO}_{2}$. Intensities have been normalized relative to the $\mathrm{O} 2 s$ band.

strate that at low doping level the extra electrons associated with $\mathrm{Nb}$ doping are localized mainly on $\mathrm{Ti}$ rather than $\mathrm{Nb}$, so the lightly doped material is better formulated as $\mathrm{Ti}(\mathrm{IV})_{1-2 x} \mathrm{Ti}(\mathrm{III})_{x} \mathrm{Nb}(\mathrm{V})_{x} \mathrm{O}_{2}$ rather than $\mathrm{Ti}(\mathrm{IV})_{1-x} \mathrm{Nb}(\mathrm{IV})_{x} \mathrm{O}_{2}$. The present photoemission measurements thus concur with conclusions drawn from a broad range of techniques including $\mathrm{X}$-ray absorption spectroscopy (XAS), ${ }^{71-73}$ ESR, optical spectroscopy, ${ }^{67}$ and transport measurements. $^{6-9}$ However, our conclusions differ from those inferred from work on $\mathrm{Nb}$-doped $\mathrm{TiO}_{2}$ grown by oxygen-plasma-assisted MBE. ${ }^{28,29}$ Here $\mathrm{x}$-ray photoemission spectra in material formulated as $\mathrm{Ti}_{1-x} \mathrm{Nb}_{x} \mathrm{O}_{2}(0.1<x$ $<0.4)$ were free of new states in the bulk band gap but the photoemission intensity increased across the $\mathrm{O} 2 p$ valence band. This led to the proposal that the new $\mathrm{Nb} 4 d$ states overlap the $\mathrm{O} 2 p$ valence-band states and are therefore very much "deeper" than expected from transport measurements on very lightly doped $\mathrm{TiO}_{2}$. However, consideration of the oxygen pressure during MBE growth leads us to believe that oxidation of $\mathrm{Nb}(\mathrm{IV})$ is inevitable under the growth conditions so that the $\mathrm{Nb}$ dopant is present as $\mathrm{Nb}(\mathrm{V})$ compensated by cation vacancies (or perhaps oxygen interstitials). Cluster calculations revel that there is significant $\mathrm{Nb}-\mathrm{O}$ covalency in the both doped-uncompensated and doped-compensated material, ${ }^{76}$ which $\mathrm{O}$ introduces $\mathrm{Nb} 4 d$ character into the $2 p$ valence-band states. The cross section for ionization of $\mathrm{Nb}$ $4 d$ states is very much bigger than the cross section for ionization of Ti $3 d$ or O $2 p$ states, and the increased valenceband intensity that arises from $\mathrm{Nb}$ doping is easily rationalized within the framework of a simple Gelius-type model.

Comparison of the present results for $\mathrm{Nb}$-doped $\mathrm{TiO}_{2}$ with 
earlier work on $\mathrm{V}$-doped $\mathrm{TiO}_{2}$ reveal a simple qualitative difference between the two systems: in the V-doped material electrons are trapped on the dopant atom rather than on host cation sites. ${ }^{10,11}$ This difference may be ultimately traced to the differing Coulomb potentials associated with the two differing dopant atoms.

\section{ACKNOWLEDGMENTS}

J. R. is grateful to the Soros Foundation for financial support. We thank Dr. G. Beamson and Mr. D. Kinder for technical assistance during $\mathrm{x}$-ray photoemission measurements. We also acknowledge financial support from EPSRC.
*Corresponding author. Electronic address: russ.egdell@chem.ox.ac.uk

${ }^{1}$ Semiconductors: Physics of Non-Tetrahedrally Bonded Binary Compounds III, edited by O. Madelung, Landolt-Bornstein, New Series, Group III, Vol. 17, Pt. g (Springer Verlag, Berlin, 1984).

${ }^{2}$ B. O. Marinder and A. Magneli, Acta Chem. Scand. 12, 1345 (1958).

${ }^{3}$ W. Rüdorff and H.-H. Luginsland, Z. Anorg. Allg. Chem. 334, 125 (1964).

${ }^{4}$ K. Sakata, J. Phys. Soc. Jpn. 26, 1067 (1969).

${ }^{5}$ K. Sakata, I. Nishida, M. Matsushima, and T. Sakata, J. Phys. Soc. Jpn. 27, 506 (1969).

${ }^{6}$ P. F. Chester, J. Appl. Phys. 32, 866 (1961).

${ }^{7}$ M. Itakura, N. Nizeki, H. Toyoda, and H. Iwasaki, Jpn. J. Appl. Phys. 6, 311 (1967).

${ }^{8}$ J. W. DeFord and O. W. Johnson, J. Appl. Phys. 54, 889 (1983).

${ }^{9}$ T. Okamura and H. Okushi, Jpn. J. Appl. Phys., Part 2 32, L454 (1993).

${ }^{10}$ A. E. Tavener, C. Rayden, S. Warren, A. Gulino, P. A. Cox, and R. G. Egdell, Phys. Rev. B 51, 6833 (1995).

${ }^{11}$ R. G. Egdell, A. Gulino, C. Rayden, G. Peacock, and P. A. Cox, J. Mater. Chem. 5, 499 (1995).

${ }^{12}$ K. Mizushima, M. Tanaka, and S. Iida, J. Phys. Soc. Jpn. 32, 1519 (1972).

${ }^{13}$ K. Mizushima, M. Tanaka, A. Asai, S. Iida, and J. B. Goodenough, J. Phys. Chem. Solids 40, 1129 (1979).

${ }^{14}$ A. Vejux and P. Courtine, J. Solid State Chem. 23, 93 (1978).

${ }^{15}$ J. F. Baumard and E. Tami, J. Chem. Phys. 67, 857 (1977).

${ }^{16}$ N. G. Eror, J. Solid State Chem. 38, 281 (1981).

${ }^{17}$ J-F. Marucco, B. Poumellec, J. Gautron, and P. Lemasson, J. Phys. Chem. Solids 46, 709 (1985).

${ }^{18}$ E. Tani and J. F. Baumi, J. Solid State Chem. 32, 105 (1980).

${ }^{19}$ H. Cui, K. Dwight, S. Soled, and A. Wold, J. Solid State Chem. 115, 187 (1995).

${ }^{20}$ S. Okazaki and T. Okuyama, Bull. Chem. Soc. Jpn. 56, 2159 (1983).

${ }^{21}$ K. Zakrzewska, M. Radecka, and M. Rekas, Thin Solid Films 310, 161 (1997).

${ }^{22}$ M. Z. Atashbar, H. T. Sun, B. Gong, W. Wlodarski, and R. Lamb, Thin Solid Films 326, 238 (1998)

${ }^{23}$ R. K. Sharma, M. C. Bhatnagar, and G. L. Sharma, Appl. Surf. Sci. 92, 647 (1996)

${ }^{24}$ S. A. Chambers, Y. Gao, S. Thevuthasan, Y. Liang, N. R. Shivaparan, and R. J. Smith, J. Vac. Sci. Technol. A 14, 1387 (1996).

${ }^{25}$ Y. Gao and S. A. Chambers, J. Mater. Res. 11, 1025 (1966).

${ }^{26}$ S. Thevuthasan, N. R. Shivaparan, R. J. Smith, Y. Gao, and S. A. Chambers, Appl. Surf. Sci. 115, 381 (1997).

${ }^{27}$ Y. Gao, Y. Liang, and S. A. Chambers, Surf. Sci. 365, 638 (1996).

${ }^{28}$ Y. Gao, Y. Liang, and S. A. Chambers, Surf. Sci. 348, 17 (1996).

${ }^{29}$ S. A. Chambers, Y. Gao, Y. J. Kim, M. A. Henderson, S. Thevuthasan, S. Wen, and K. L. Merkle, Surf. Sci. 365, 625 (1996).
${ }^{30}$ G. Thornton, A. F. Orchard, and C. N. R. Rao, Phys. Lett. 54A, 235 (1975).

${ }^{31}$ N. Beatham and A. F. Orchard, J. Electron Spectrosc. Relat. Phenom. 16, 77 (1979).

${ }^{32}$ J. H. Xu, T. Jarlborg, and A. J. Freeman, Phys. Rev. B 40, 7939 (1989).

${ }^{33}$ T. Sakata, K. Sakata, and I. Nishida, Phys. Solid State 20, K155 (1967).

${ }^{34}$ A. A. Bolzan, C. Fong, B. J. Kennedy, and C. J. Howard, J. Solid State Chem. 113, 9 (1994).

${ }^{35}$ G. Beamson, D. Briggs, S. F. Davies, I. W. Fletcher, D. T. Clark, J. Howard, U. Gelius, B. Wannberg, and P. Balzer, Surf. Interface Anal. 9, 541 (1990).

${ }^{36}$ R. H. Day, P. Lee, E. P. Saloman, and D. J. Nagel, J. Appl. Phys. 52, 6965 (1981).

${ }^{37}$ F. H. Jones, K. Rawlings, J. S. Foord, R. G. Egdell, J. B. Pethica, B. M. R. Wanklyn, S. C. Parker, and P. M. Oliver, Surf. Sci. 359, 107 (1996).

${ }^{38}$ K. Yoshimura, T. Miki, S. Iwama, and S. Tanemura, Thin Solid Films 282, 235 (1996).

${ }^{39}$ B. O. Marinder, Acta Chem. Scand. 15, 707 (1961).

${ }^{40}$ K. Sakata, J. Phys. Soc. Jpn. 26, 582 (1969).

${ }^{41}$ J. F. Marucco, R. Tetot, P. Gerdanian, and C. Picard, J. Solid State Chem. 18, 97 (1976).

${ }^{42}$ C. N. R. Rao, G. R. Rao, and G. V. Subba Rao, J. Solid State Chem. 6, 340 (1973).

${ }^{43}$ S. M. Shapiro, J. D. Axe, G. Shirane, and P. M. Racah, Solid State Commun. 15, 377 (1974).

${ }^{44}$ J. B. Goodenough, Prog. Solid State Chem. 5, 145 (1971).

${ }^{45}$ N. Beatham, P. A. Cox, R. G. Egdell, and A. F. Orchard, Chem. Phys. Lett. 69, 479 (1980).

${ }^{46}$ A. Kotani and Y. Toyazawa, J. Phys. Soc. Jpn. 37, 912 (1974).

${ }^{47}$ J. N. Chalzalviel, M. Campagna, G. K. Wertheim, and H. R. Shanks, Phys. Rev. B 16, 697 (1977).

${ }^{48}$ G. K. Wertheim, Chem. Phys. Lett. 65, 377 (1979).

${ }^{49}$ Y. J. Kim, Y. Gao, and S. A. Chambers, Appl. Surf. Sci. 120, 250 (1997).

${ }^{50}$ R. G. Egdell, S. Eriksen, and W. R. Flavell, Solid State Commun. 60, 835 (1986).

${ }^{51}$ R. Dixon, R. G. Egdell, and G. Beamson, J. Chem. Soc., Faraday Trans. 91, 3495 (1995).

${ }^{52}$ R. G. Egdell and S. C. Parker, in Science of Ceramic Interfaces, edited by J. Nowotny (Elsevier, Amsterdam, 1991).

${ }^{53}$ Z. Zhang, S. P. Jeng, and V. E. Henrich, Phys. Rev. B 43, 12004 (1990).

${ }^{54}$ D. Morris, R. Dixon, F. H. Jones, Y. Dou, R. G. Egdell, S. W. Downes, and G. Beamson, Phys. Rev. B 55, 16083 (1997).

${ }^{55}$ S. Shin, S. Suga, M. Taniguchi, M. Fujisawa, H. Kanzaki, A. Fujimori, H. Daimon, Y. Ueda, K. Kosuge, and S. Kachi, Phys. Rev. B 41, 4993 (1990).

${ }^{56}$ A. Howard, C. E. J. Mitchell, D. Morris, R. G. Egdell, and S. C. Parker Surf. Sci. (to be published).

${ }^{57}$ M. Sander and T. Engel, Surf. Sci. 302, L263 (1994). 
${ }^{58}$ D. Novak, E. Garfunkel, and T. Gustafsson, Phys. Rev. B 50, 5000 (1994).

${ }^{59}$ S. Fischer, A. W. Munz, K. D. Schierbaum, and W. Göpel, Surf. Sci. 337, 17 (1995).

${ }^{60}$ P. W. Murray, N. G. Condon, and G. Thornton, Phys. Rev. B 51, 10989 (1995).

${ }^{61}$ H. Onishi and Y. Iwasawa, Chem. Phys. Lett. 226, 111 (1994).

${ }^{62}$ U. Diebold, J. Lehman, T. Mahmoud, M. Kuhn, G. Leonardelli, W. Hebenstreit, M. Schmid, and P. Varga, Surf. Sci. 411, 137 (1998).

${ }^{63}$ P. M. Oliver, G. W. Watson, E. T. Kelsey, and S. C. Parker, J. Mater. Chem. 7, 563 (1997).

${ }^{64}$ H. Onishi and Y. Isasawa, Chem. Phys. Lett. 226, 111 (1994).

${ }^{65}$ U. Diebold, W. Hebenstreit, G. Leomardelli, M. Schmid, and P. Varga, Phys. Rev. Lett. 81, 405 (1998).

${ }^{66}$ U. Diebold, J. F. Anderson, K. O. Ng, and D. Vanderbilt, Phys. Rev. Lett. 77, 1322 (1996).

${ }^{67}$ M. Valigi, D. Cordischi, G. Minelli, P. Natale, P. Porta, and C. P. Kejizers, J. Solid State Chem. 77, 255 (1988).

${ }^{68}$ R. S. Roth and L. W. Coughanour, J. Res. Natl. Bur. Stand. 55, 209 (1955).

${ }^{69}$ A. D. Waldsley, Acta Crystallogr. 14, 660 (1961).

${ }^{70}$ D. Briggs and M. P. Seah, Practical Surface Analysis (Wiley,
New York, 1983).

${ }^{71}$ B. Poumellec, F. Lagnel, J. F. Marucco, and B. Touzelin, Phys. Status Solidi B 133, 371 (1986).

${ }^{72}$ F. Lagnel, B. Poumellec, and R. Cortes, J. Phys. Chem. Solids 50, 1211 (1989).

${ }^{73}$ M. R. Antonio, I. Song, and H. Yamada, J. Solid State Chem. 93, 183 (1991).

${ }^{74}$ B. Poumellec, J. F. Marucco, and B. Touzelin, Phys. Status Solidi B 137, 519 (1986).

${ }^{75}$ S. H. Vosko, L. Wilck, and M. Nusair, Can. J. Phys. 58, 1200 (1980).

${ }^{76}$ M. Casarin, C. Maccato, and A. Vittadini, Phys. Chem. Chem. Phys. 1, 3793 (1999).

${ }^{77}$ M. Casarin, E. Tondello, and A. Vittadini, Surf. Sci. 387, L1079 (1994).

${ }^{78}$ M. Casarin, C. Maccato, and A. Vittadini, Chem. Phys. Lett. 280, 53 (1997).

${ }^{79}$ M. Casarin, C. Maccato, and A. Vittadini, J. Phys. Chem. B 102, 10745 (1998).

${ }^{80}$ M. Casarin, C. Maccato, and A. Vittadini, Appl. Surf. Sci. 142, 196 (1999).

${ }^{81}$ J. J. Yeh and I. Lindau, At. Data Nucl. Data Tables 32, 1 (1985). 